Pre-print, submitted for publication to Remote Sensing of Environment. The final approved manuscript is available at 10.1016/j.rse.2017.03.029

\title{
PhenoRice: a method for automatic extraction of spatio-temporal information on rice crops using satellite data time series
}

\author{
Mirco Boschettia,*, Lorenzo Busetto ${ }^{\mathrm{a}}$, Giacinto Manfron ${ }^{\mathrm{a}}$, Alice Laborte $^{\mathrm{b}}$, Sonia Asilo , $^{\mathrm{b}, \mathrm{c}}$, Sellaperumal \\ Pazhanivelan ${ }^{\mathrm{d}}$, Andrew Nelson ${ }^{\mathrm{c}}$ \\ ${ }^{a}$ Institute for Electromagnetic Sensing of the Environment, Italian National Research Council, Via Corti 12, 20133 Milan, \\ Italy.e-mails: boschetti.m@irea.cnr.it, busetto.l@irea.cnr.it,manfron.g@irea.cnr.it \\ ${ }^{b}$ International Rice Research Institute (IRRI), Los Baños 4031, Philippines. e-mail: a.g.laborte@irri.org \\ ${ }^{c}$ Department of Natural Resources. ITC - Faculty of Geo-Information Science and Earth Observation of the University of \\ Twente.PO Box 217, 7500 AE Enschede, the Netherlands.e-mails: a.nelson@utwente.nl, s.asilo@utwente.nl \\ ${ }^{d}$ Department of Remote Sensing and GIS, Tamil Nadu Agricultural University (TNAU), Coimbatore 641003, India. e-mail: \\ pazhanivelans@gmail.com
}

\begin{abstract}
Agricultural monitoring systems require spatio-temporal information on widely cultivated staple crops like rice. More emphasis has been made on area estimation and crop detection than on the temporal aspects of crop cultivation, but seasonal and temporal information such as i) crop duration, ii) date of crop establishment and iii) cropping intensity are as important as area for understanding crop production. Rice cropping systems are diverse because genetic, environmental and management factors (GxExM combinations) influence the spatio-temporal patterns of cultivation.
\end{abstract}

We present a rule based algorithm called PhenoRice for automatic extraction of temporal information on the rice crop using moderate resolution hypertemporal optical imagery from MODIS. Performance of PhenoRice against spatially and temporally explicit reference information was tested in three diverse sites: rice-fallow (Italy), rice-other crop (India) and rice-rice (Philippines) systems.

Regional product accuracy assessments showed that PhenoRice made a conservative, spatially representative and robust detection of rice cultivation in all sites ( $r^{2}$ between 0.75 and 0.92 ) and crop establishment dates were in close agreement with the reference data $\left(r^{2}=0.98\right.$, Mean Error $=4.07$ days, Mean Absolute Error $=9.95$ days, $p<0.01$ ). Variability in algorithm performance in different conditions in each site (irrigated vs rainfed, direct seeding vs transplanting, fragmented vs clustered rice landscapes and the impact of cloud contamination) was analysed and discussed. Analysis of the maps revealed that cropping intensity and season length per site matched well with local information on agro-practices and cultivated varieties. The results show that PhenoRice is robust for deriving essential temporal descriptions of rice systems in both temperate and tropical regions at a level of spatial and temporal detail that is suitable for regional crop monitoring on a seasonal basis.

This work is licensed under a Creative Commons "Attribution-NonCommercialNoDerivatives 4.0 International" license. 


\section{Introduction}

\subsection{The challenge of mapping and monitoring rice}

Information on where and when crops are grown is fundamental to agricultural monitoring and reporting systems. The importance of remote sensing in generating this information has been identified by the Group on Earth Observations Global Agricultural Monitoring Initiative (GEOGLAM - Group on Earth Observation (2013)). One component of GEOGLAM emphasises the need for research on the development of best practices for agricultural monitoring in diverse environments, and is closely associated with the goal of the Joint Experiment of Crop Assessment and Monitoring (JECAM, 2015) to reach a convergence of approaches for monitoring protocols. This component includes methods that are suited for particular environments and crops that are specific to those environments as well as methods that can work across different environments. Methods that are robust across different environments are advantageous for mapping and monitoring staple crops such as wheat, maize and rice, each of which is grown in 120 or more countries with a combined harvested area of 568 million hectares in 2014 (FAO, 2016). The importance of these staple crops for food security and the geographic extent and range of environments in which they are cultivated requires robust mapping and monitoring methods that can be used at scale (Whitcraft et al., 2015) and which can cope with the expected variability in crop environments.

Rice, a staple crop, has sufficient genetic diversity to permit its cultivation across a range of environments. Rainfall in rice-growing areas can vary from over 5,000 $\mathrm{mm} \mathrm{y}^{-1}$ along Myanmar's Arakan Coast to less than $100 \mathrm{~mm} \mathrm{y}^{-1}$ in Al Hasa Oasis in Saudi Arabia; average temperature during the rice growing season can vary from highs of $33^{\circ} \mathrm{C}$ in Sindh, Pakistan, to lows of $17{ }^{\circ} \mathrm{C}$ in northern Japan and rice can be cultivated from sea level up to $2600 \mathrm{~m}$ on the terraces of Nepal and Bhutan (Boschetti et al., 2014). Rice can also be cultivated under a wide range of management conditions: from highly mechanised, irrigated, single summer cropping - e.g., Italy, Japan, the U.S., Australia, Brazil, to the more marginal rainfed rice systems across Latin America, sub-Saharan Africa, and South and South-east Asia; in rotation with other crops such as the vast rice/wheat systems of India and China, and intensive, irrigated triple cropping in Indonesia and Vietnam (Boschetti et al., 2014; GRiSP (Global Rice Science Partnership), 2016). This variability in

\footnotetext{
* Corresponding author

Email addresses: boschetti.m@irea.cnr.it (Mirco Boschetti), busetto.1@irea.cnr.it (Lorenzo Busetto), a.nelson@utwente.nl (Andrew Nelson) 
Pre-print, submitted for publication to Remote Sensing of Environment. The final approved manuscript is available at 10.1016/j.rse.2017.03.029

rice cultivation leads to three particular challenges for remote sensing based observation and monitoring: variation in growing period, variation in date of crop establishment (sowing or transplanting) and variation in cropping intensity (Nelson et al., 2014).

Although detecting the common practice of agronomic flooding of the rice paddy prior to crop establishment has been demonstrated (Xiao et al., 2002) and evaluated (Boschetti et al., 2014) as a component of remote sensing methods to detect rice growing areas, the subsequent crop growth rate in the vegetative and reproductive phases (from germination to flowering) can vary depending on variety and weather (GRiSP (Global Rice Science Partnership), 2016). A short duration, modern rice variety with a growing period of 90 days in the tropics may reach flowering in 30 to 40 days after transplanting, whereas a long duration, traditional variety with a growing period of 160 days in a temperate climate may take up to 120 days to reach flowering. Farmers in temperate, sub-tropical and tropical areas may choose short, medium or long duration varieties to suit local conditions, their own preferences, or to match market demands (Calingacion et al., 2014; Laborte et al., 2015). The influence of social and economic factors in varietal choice means that the crop growth rate is not solely related to latitude or cumulated growing degree days. Robust methods for monitoring the rice crop need to accommodate this variability in growth duration.

The choice of when to establish a crop can be driven by several factors such as: temperature constraints to avoid both low and high limiting temperature conditions in key stages of the season; water availability in water-limited environments; temporal variability in water salinity; the risk of submergence, or combinations of those (Wassmann et al., 2009). Thus, it is possible to map out the potential growing season for rice based on climatic suitability parameters (while ignoring other environmental factors such as soil constraints (Haefele et al., 2014)). However, in many parts of South, South-east and East Asia, where 90\% of the world's rice is produced, the sub-tropical and tropical temperatures, the abundance of water in the monsoon season and the increasing reliance on irrigation in the dry season mean that rice can and is grown at almost any time of year across the region (Boschetti et al., 2015b). Other factors that play a role in the choice of crop establishment date include labour availability, the level of agricultural mechanization and establishment method. These mean that crop establishment dates can vary substantially over small distances (Asilo et al., 2014). Thus, methods for monitoring rice must be able to accommodate and represent a variability in crop establishment date that is not purely driven by climate.

Where temperature and water availability allow, the introduction of short and medium duration varieties means that rice can be cropped more than once per year on the same plot of land. Double and triple cropping of rice accounts for 55 million ha of harvested rice area in countries like India, Bangladesh, Myanmar,

This work is licensed under a Creative Commons "Attribution-NonCommercialNoDerivatives 4.0 International" license. 
Pre-print, submitted for publication to Remote Sensing of Environment. The final approved manuscript is available at 10.1016/j.rse.2017.03.029

Thailand, Vietnam, Philippines, Malaysia, Indonesia and China (Dawe et al., 2010) as well as in smaller areas in Madagascar, Nigeria, Mali, Guinea, Senegal and Côte d'Ivoire (Balasubramanian et al., 2007). Rice is also cropped in rotation with other cereals (such as wheat or maize), pulses (such as gram or pigeon pea), oil and vegetable crops, and there are many double and triple cropping combinations depending on local preferences, markets, input and labour costs, and environmental constraints. Thus, the cropping intensity of rice in major tropical and subtropical rice growing regions can vary over small geographic areas independently of the climatically defined length of growing season and methods for monitoring rice must be able to accommodate and represent this variability too.

These three factors lead to complex spatio-temporal patterns of rice production situations in major rice growing regions. We argue therefore that there is the need to develop methods that are robust enough to capture spatio-temporal patterns across a wide range of rice environments. Such information would support several important research and development needs, such as: better characterization and understanding of rice crop environments; improved modelling of yields and crop health; better targeted interventions to increase the productivity, sustainability and profitability of rice production, and; improved modelling of rice production and production constraints.

\subsection{Optical remote sensing based methods of mapping and monitoring rice}

Remote sensing based rice mapping has been performed since the late 1980s using single and multitemporal images such as Landsat and MODIS. Rice detection has been further improved by multisource algorithms that integrate multitemporal (Barbosa et al., 1996), multisensor (Fang et al., 1998) images or GIS information (Li et al., 2003). To achieve high accuracy, some methods have also included complex multistep hybrid classification approaches that optimize the mapping of specific environments (Turner and Congalton, 1998). Despite the good mapping results provided by image based classifications, these procedures are demanding and time-consuming in terms of operator intervention, and supervised and unsupervised classification require training selection or a posteriori labelling, respectively. Moreover, the good results from specific study sites are not always directly exportable to other contexts and geographic locations.

More robust detection methods with a higher generalization capability have been based on multitemporal imagery, from both passive and active sensors (e.g., Le Toan et al. (1997)). To guarantee the necessary frequency of image acquisition, quasi-daily observation acquired from moderate resolution optical data have been commonly used in two different classification approaches: $i$ ) supervised temporal signal analysis (signal matching) and ii) rule based analysis. An example of the first approach is the rice cropping systems maps produced by Gumma et al. (2011) for South Asia. The method has generated accurate maps on a wide area,

This work is licensed under a Creative Commons "Attribution-NonCommercialNoDerivatives 4.0 International" license. 
Pre-print, submitted for publication to Remote Sensing of Environment. The final approved manuscript is available at 10.1016/j.rse.2017.03.029

however its application to another region would involve another round of time consuming operator analysis and decision making in the classification, grouping and labelling phase. The second approach defines a series of detection criteria on the basis of well-known temporal characteristics of rice cultivation. One of the more cited methods for rice detection belonging to this second approach to classification is the one proposed by Xiao et al., who used Spot Vegetation (VGT) data (Xiao et al., 2002) and later MODIS data (Xiao et al., 2005) to map rice flooding and rice cultivated area in China, and South and South-east Asia (Xiao et al., 2006). The method is based on the detection of agronomic (i.e., deliberate) flooding of the rice fields before the crop is established and subsequent rapid growth of the crop within a fixed time period after flooding. Because these two characteristics are common to many rice cultivation practices (with the exception of upland rice, deep water rice, dry direct-seeded rice and other relatively minor rice ecosystems or rice management practices), the method has potential for operational monitoring of rice cultivated area at regional scale. However, demonstrations of this method revealed that false positives can occur when it is applied in ecosystems different from the ones where it was developed originally (Peng et al., 2011) and when external knowledge on local crop calendar and agro-practices are not considered (Manfron et al., 2012). In any case, the above examples do not account for or provide information on variation in growing period, variation in date of crop establishment and variation in cropping intensity.

Although mapping the extent or area of crops like rice has received a lot of attention, the retrieval of temporal information has not been adequately investigated despite the fact that many methods rely on the temporal signal from remotely sensed time series data to separate rice from other land covers. Sakamoto et al. $(2005,2006)$ used wavelet analysis to extract seasonality information from multitemporal MODIS imagery for rice crops in Japan and the Mekong delta. Nguyen et al. (2012) and Asilo et al. (2014) used labelling and grouping of unsupervised classifications of VGT data in the Mekong delta and MODIS data in the Philippines, respectively, to generate rice crop calendars. Tornos et al. (2015) studied the temporal characteristics of rice cropping systems in Spain and demonstrated that time series of vegetation indices can be used to analyse changes in flooding period (hydro period).

Table 1 provides a comparative view of exemplar rice mapping and monitoring studies. We characterise them to highlight their contribution to temporal information on rice cropping systems, specifically in providing information at scale on $i$ ) intensity, ii) seasonality and iii) crop duration. We also note if the methods have been validated against field or high resolution (HR) imagery in multiple environments. Based on our review of methods and studies, there are several rice (crop) detection methods but none of those that we are aware of has been validated to be robust for its ability to capture the three temporal aspects of rice

This work is licensed under a Creative Commons "Attribution-NonCommercialNoDerivatives 4.0 International" license.

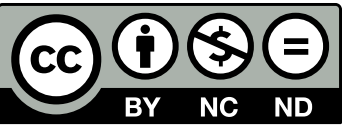


Pre-print, submitted for publication to Remote Sensing of Environment. The final approved manuscript is available at 10.1016/j.rse.2017.03.029

cultivation (duration, seasonality and cropping intensity) across different environments.

From the summary in Table 1, we argue that a robust method for detection and estimation of these spatiotemporal characteristics at regional scale should rely on the most common aspects of rice crop cultivation. Agronomic flooding of the rice field is a unique characteristic that distinguishes rice from other field crops. Therefore, we start with the assertion that any operational detection method for lowland rice which relies on the interpretation of optical time series imagery must be robust in detecting agronomic flooding with low commission and omission errors. The variation across environments in the crop growth rate after crop establishment should be incorporated into rice detection rules. We assert that this requires a robust exploitation of crop specific metrics to improve the rice detection capability and reduce the dependency on locally tuned thresholds. Detection of flooding and increase in post-flooding biomass requires high-frequency multitemporal data and hence, at the moment, the use of moderate resolution imagery. We assert that when moderate resolution data are used to study agricultural systems, their most valuable contribution is in the inter-annual and intra-annual analysis of crop practices and phenology and not as an area estimation method.

Based on these three criteria (robust flood detection, robust rice crop phenology detection and emphasizing temporal information over area information), we developed a method that is able to detect pixels where rice is cultivated (one or more times per year) in a robust way. The emphasis is on identifying sufficient representative samples to further perform time series analysis and retrieve statistically sound and spatially explicit phenometrics that characterise rice production systems.

\subsection{Objectives}

The objectives of this research were to develop and assess the performance of a rice crop phenological detection method based on automatic identification of rice cultivated areas. The method must i) be able to provide diagnostic information on water management, ii) generate minimal confusion with other crops/target, and iii) be able to deal with variation in the start, length and number of seasons while providing reliable and representative phenological information for each detected season.

To reach these objectives and requirements we developed the PhenoRice algorithm and we performed a number of tests and experiments using MODIS satellite data as inputs, and used previously published, high resolution, spatially and temporally explicit data on rice area and seasonality for validation. Unlike previous studies, we:

1. Assessed PhenoRice's rice detection capability by comparing our results with high resolution maps rather than rice harvested area statistics from administrative units;

This work is licensed under a Creative Commons "Attribution-NonCommercialNoDerivatives 4.0 International" license. 
Pre-print, submitted for publication to Remote Sensing of Environment. The final approved manuscript is available at 10.1016/j.rse.2017.03.029

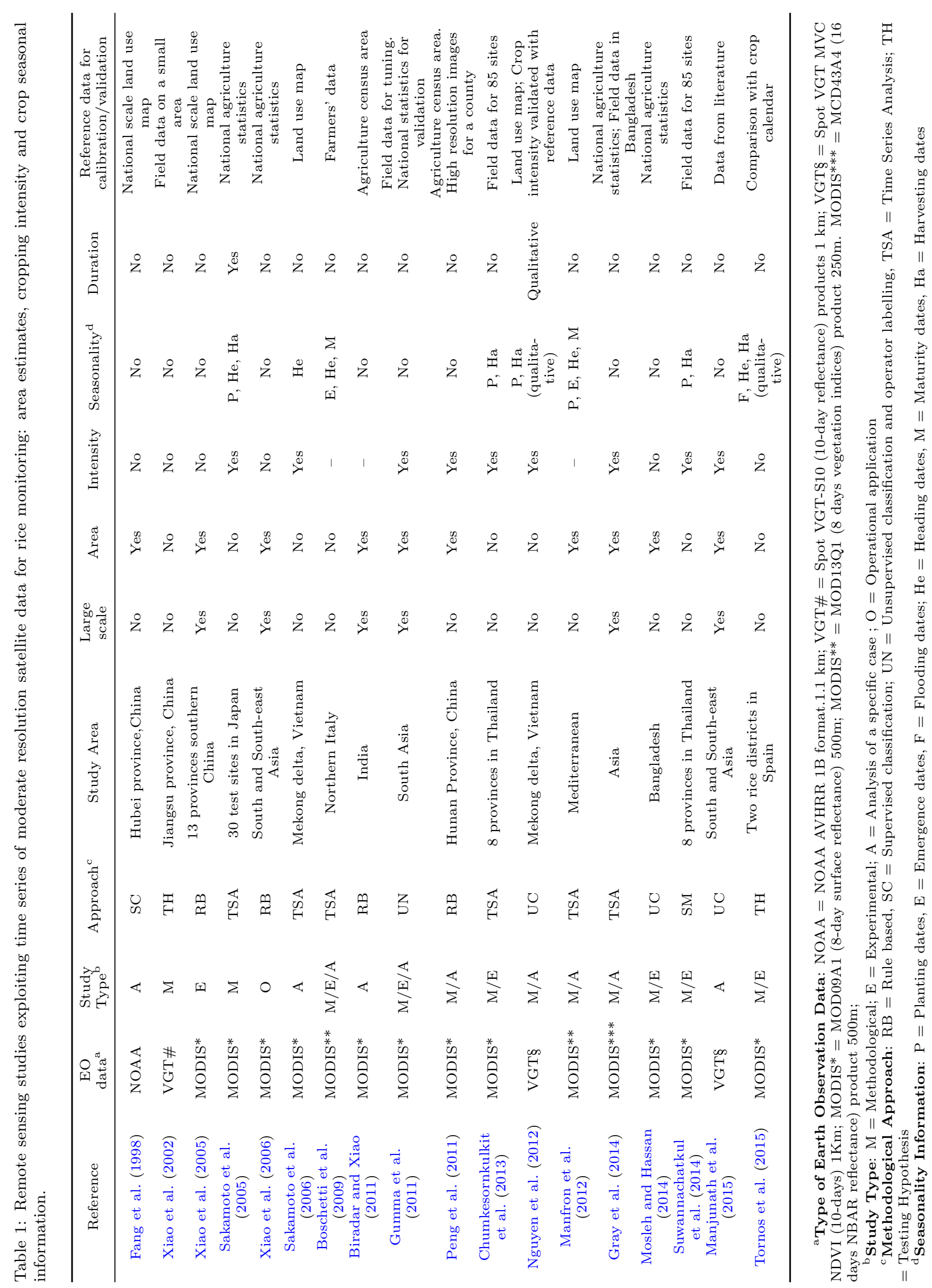

This work is licensed under a Creative Commons "Attribution-NonCommercialNoDerivatives 4.0 International" license. 
Pre-print, submitted for publication to Remote Sensing of Environment. The final approved manuscript is available at 10.1016/j.rse.2017.03.029

2. Demonstrated the detection capability of PhenoRice in different environments, ranging from temperate to tropical (in both dry and wet seasons);

3. Analysed the performance of PhenoRice in providing multiseason phenological information.

Based on our review of the literature, this is the first time that multiseason rice phenology across different systems has been detected using remote sensing based information and validated using high resolution data in different environments.

\section{The PhenoRice algorithm: theoretical basis}

The PhenoRice algorithm is a new approach for estimating key dates in rice crop cultivation, by analysing time series of spectral indices (SIs) derived from moderate resolution satellite imagery. It provides a reliable estimation of the spatial variability of the dates of crop establishment and flowering over large areas, irrespective of the characteristics of rice cultivation in different environments, such as crop establishment method and dates (crop calendar) and cropping intensity.

Development of the algorithm was based on the works of Xiao et al. (2005, 2006), where a rule based method is used to identify a rice crop when a clear and unambiguous flood condition is detected before a consistent and rapid vegetation growth. To do this, within PhenoRice a spectral index sensitive to soil submergence (NDFI - Normalized Difference Flood Index, Boschetti et al. (2014) -) is used to detect agronomic flooding and a standard vegetation index related to crop biomass, Enhanced Vegetation Index (EVI - Huete et al. (2002)) used to detect subsequent crop growth and harvesting (Boschetti et al., 2009).

We assume that PhenoRice is suited to situations where rice is transplanted or wet seeded under irrigated or rainfed conditions, which accounts for the vast majority of rice growing areas (90\% of global rice production - GRiSP (Global Rice Science Partnership) (2013)). We also assume that performance will be limited in rice growing areas where fields are sloping and where dry seeding is practiced. These areas constitute a small proportion of the global rice area.

The following sections briefly illustrate the main features of the algorithm and its data requirements.

\subsection{Input data}

PhenoRice uses time series information derived from MODIS Land Surface Products. In particular:

1. MODIS TERRA and AQUA time series derived from the 250m 16-day composite vegetation index products (MOD13Q1/MYD13Q1 - Didan (2006)) v005, for the following parameters:

a) EVI;

This work is licensed under a Creative Commons "Attribution-NonCommercialNoDerivatives 4.0 International" license. 
Pre-print, submitted for publication to Remote Sensing of Environment. The final approved manuscript is available at 10.1016/j.rse.2017.03.029

b) NDFI, computed from red $\left(b_{1}\right)$ and SWIR $\left(b_{7}\right)$ reflectances as $\frac{\left(b_{1}-b_{7}\right)}{\left(b_{1}+b_{7}\right)}$;

c) Blue band Reflectance $\left(b_{3}\right)$;

d) DOY (Day of The Year) of Composite;

e) Usefulness Index and Pixel Reliability quality indicators.

Since MOD13Q1 and MYD13Q1 are based on compositing periods shifted by 8 days between each other, the time series derived from the two 16-day products has a theoretical 8 day frequency.

2. MODIS Terra daytime Land Surface Temperature (LST) time series, derived from the TERRA $1 \mathrm{~km}$ 8-Day LST product (MOD11A2 - Wan (2006)), resampled to 250m spatial resolution. This represents the average values of clear-sky LSTs observed from daytime acquisitions over an 8-day period.

An additional input, a mask file, can be provided to identify pixels that should not be processed. This mask can be derived from recent land cover maps highlighting agricultural areas, though more complex masks can be derived by exploiting expert knowledge of the typical characteristics of the rice-cultivated areas in the region of interest (e.g. masks based on topographical attributes such as altitude or slope and masks excluding areas known to be permanently cultivated with other crops).

\subsection{Algorithm description}

For each MODIS pixel (except those excluded by the mask), PhenoRice determines if it has a high probability of belonging to a rice area, estimates the rice crop establishment and flowering dates, and then computes the combined length of the vegetative and reproductive phases as the difference between these two dates (i.e. from flowering to crop establishment). We focus, therefore, on the estimation of crop stage occurrence related to the location-specific management and genetics of the rice crop. The EVI time series of each pixel is smoothed using a Savitzky-Golay two-iteration method to reduce noise due to cloud contamination or variable acquisition angles. The smoothing method assigns weights to the EVI values according to estimated data quality (Boschetti et al., 2015b) based on information contained in the Pixel Reliability, Usefulness Index and blue reflectance time series. Additionally, the smoothing method uses the true dates of acquisition for each pixel (as reported in the "DOY of composite" MODIS band) to improve adherence of the smoothed time series to the true temporal changes in ground reflectance. The resulting smoothed time series is adapted to the upper envelope of the original curve.

The smoothed EVI signal is analysed to identify all local minima and maxima within the time series. Following Manfron et al. (2012), these minima and maxima are analysed on the basis of agronomic criteria

This work is licensed under a Creative Commons "Attribution-NonCommercialNoDerivatives 4.0 International" license. 
Pre-print, submitted for publication to Remote Sensing of Environment. The final approved manuscript is available at 10.1016/j.rse.2017.03.029

to determine the presence of a "rice cycle signal" in the time series. Pixels that meet these criteria are labelled as rice, and their rice crop establishment and rice crop flowering dates are estimated. PhenoRice can detect multiple growing seasons for a pixel within the analysed time series. This is achieved by splitting the time series into as many as four periods, each representing a possible period when rice flowering may occur, and conducting a separate analysis on each one. These periods are set by default to the four calendar seasons, but the starting date and duration of each can be adjusted by the user.

For each period, each pixel is analysed as follows:

1. Check if the pixel belongs to a rice-cultivated area: Whether the pixel belongs to a rice cultivated area during the selected period is checked using the following procedure:

a) The average EVI value within the time period must be below a specified threshold $\left(E V I_{a v g_{-} t h}\right)$. This criterion reduces misclassification problems with evergreen forests;

b) The maxima of the EVI curve within the time period are checked using the following criteria:

- EVI of the maximum is above a specified threshold $\left(E V I_{\text {max_th }}\right)$;

- A consistent increase (decrease) in EVI is observed before (after) the maximum. In particular, the existence of a sequence of at least three positive (negative) EVI first-derivatives in a temporal window of five periods centred on the maximum is checked;

If more than one maximum is found, the one with the higher EVI value is kept, and assumed to be a potential crop flowering point. This criterion allows local maxima, due to residual noise in the smoothed time series, to be discarded. If no suitable maxima are found, the pixel is labelled as non-rice and further processing is skipped.

c) The minima of the curve are evaluated against the following criteria:

- The time difference between the date of the minimum and that of the maximum $(\Delta t)$ identified in b) must fall within a specified interval $\left[\Delta t_{\min }, \Delta t_{\max }\right]$ based on prior knowledge of the dominant rice varieties and the typical combined length of the vegetative and reproductive phases in the analysed area;

- Meteorological conditions on the day of the minimum are favourable for rice crop establishment based on a MODIS LST value above a specified threshold $\left(L S T_{t h}\right)$;

- The minimum is below a specified EVI threshold $\left(E V I_{m i n \_t h}\right)$;

This work is licensed under a Creative Commons "Attribution-NonCommercialNoDerivatives 4.0 International" license. 
Pre-print, submitted for publication to Remote Sensing of Environment. The final approved manuscript is available at 10.1016/j.rse.2017.03.029

- A flood signal is detected within a time window of specified width $\left(\right.$ win $\left._{f l}\right)$ centred on the minimum, based on the value of the NDFI index. The criteria used for flood identification is $N D F I \geq 0$ (Boschetti et al., 2014);

- A consistent increase in EVI is observed after the minimum. In particular, the existence of a sequence of at least three positive EVI first-derivatives in a temporal window of five periods is checked;

- The maximum identified in b) is followed by a fast decrease in EVI, due to crop senescence and harvesting. In particular, the algorithm checks if EVI decreases by more than decr $_{t h} \%$ of the amplitude of the min-max range in a time window of specified width after the maxima $\left(\right.$ win $\left._{\text {decr }}\right)$;

If no minimum satisfies all of the above-mentioned requirements, the pixel is labelled as non-rice in the period and further analysis is skipped.

2. Estimate crop establishment and flowering dates: The crop establishment date corresponds to the date of the latest retained minimum (that is, the one closest to the retained maximum). The flowering date, on the other hand, corresponds to the mid-point date of the period during which the EVI smoothed signal remains above the $90^{\text {th }}$ percentile of the min-max range. A minimum can however satisfy all criteria for local maxima positioned in two adjacent time periods. In this case, the stronger of the two maxima is considered for computing the flowering date. Choosing the higher maximum reduces the chance of misidentifying peaks in vegetation signal as rice. Such peaks can be caused by subsequent crops (such as short duration pulses grown on residual moisture immediately after the rice crop), ratooning (where the rice stubble is left to grow again) or weeds (where the field is left fallow for some period after the rice crop).

Crop intensity is finally computed as the number of periods for which valid establishment dates are identified. A flow chart depicting the main phases of the pixel-based processing is shown in Figure 1.

This work is licensed under a Creative Commons "Attribution-NonCommercialNoDerivatives 4.0 International" license. 
Pre-print, submitted for publication to Remote Sensing of Environment. The final approved manuscript is available at $10.1016 /$ j.rse.2017.03.029

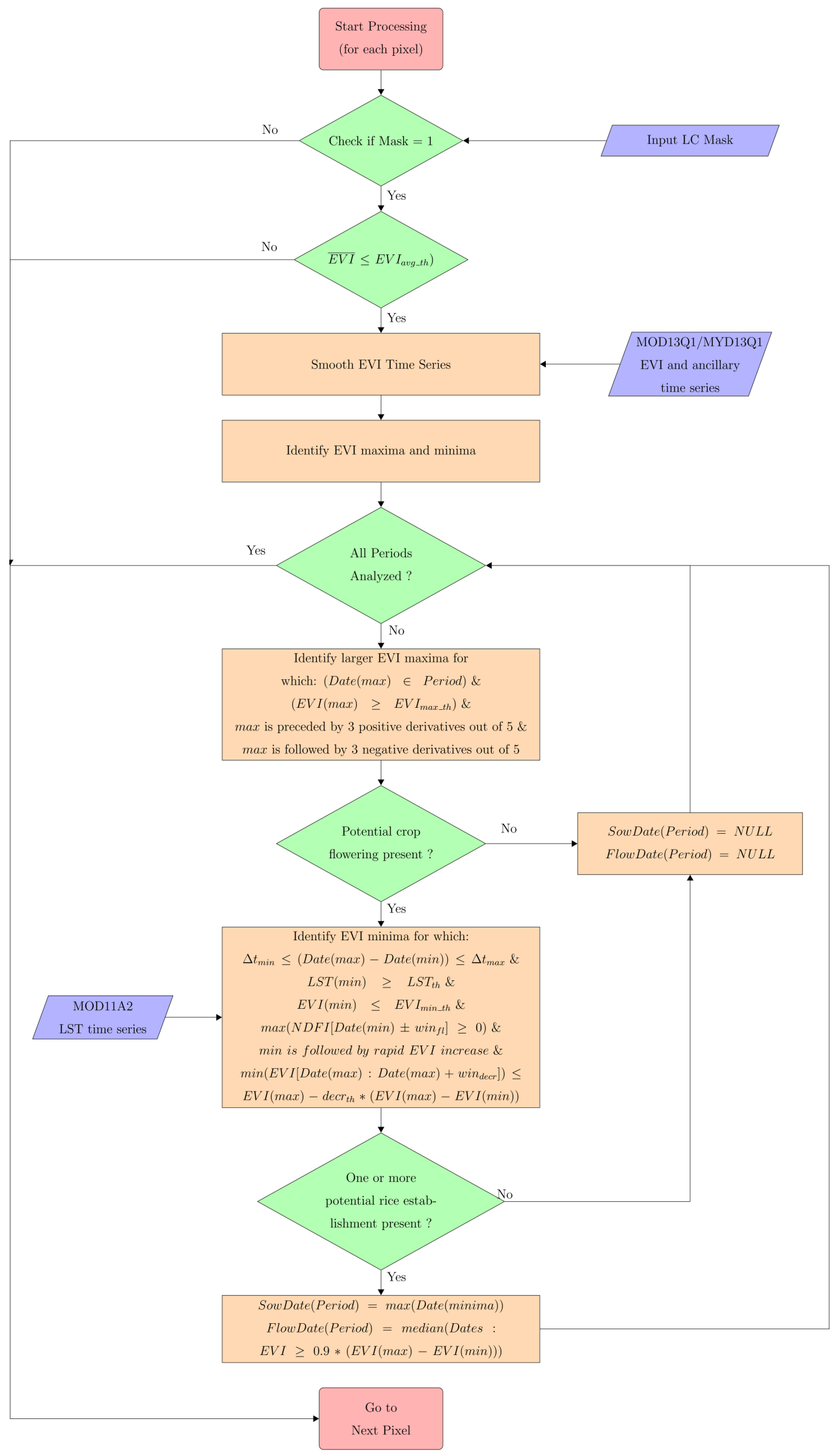

Figure 1: Flowchart of the pixel-based processing scheme of the PhenoRice algorithm

This work is licensed under a Creative Commons "Attribution-NonCommercialNoDerivatives 4.0 International" license. 
Pre-print, submitted for publication to Remote Sensing of Environment. The final approved manuscript is available at 10.1016/j.rse.2017.03.029

\subsection{Software implementation}

PhenoRice has been implemented as an IDL (Interactive Data Language) v.8.3 application. The application allows the operator to modify the settings and thresholds used in the different detection criteria. In particular the number of periods to be considered in the analysis and their temporal limits can be changed to cope with the characteristics of rice cultivation systems in different areas. For example, in temperate areas (where rice is usually grown in spring/summer and only one rice season is possible), PhenoRice can be run by considering a single time period, thus considerably speeding-up computation and avoiding possible misclassification in seasons in which rice establishment cannot happen. Conversely, in subtropical and tropical areas (where multiple rice seasons may be present in the same year), the operator can set multiple periods that are roughly centred on the known flowering periods of each season, allowing for a more efficient detection of the different seasons.

The application uses MODIS time series automatically produced by the MODIStsp "R" package for MODIS data download and pre-processing (Busetto and Ranghetti, 2016). It automatically detects which dates of the MODIS time series are required to apply PhenoRice on the basis of $i$ ) processing parameters specified by the user, and ii) the year of interest for the analysis, and automatically creates all the required multitemporal input files. In particular, the length of the time series required for PhenoRice is governed by i) the number and length of periods to be analysed, and $i$ ) the width of the $\Delta t_{\max }$ (i.e., the upper limit of the $\Delta t$ processing parameter) and win decr windows. Figure 2 shows an example of the data requirements for a common scenario, in which a solar year of interest is divided into four equal periods: $\operatorname{setting} \Delta t_{\max }$ and win $_{\text {decr }}$ to the values used in this study requires a time series that spans from the middle of August of the preceding year until the middle of March of the following year.

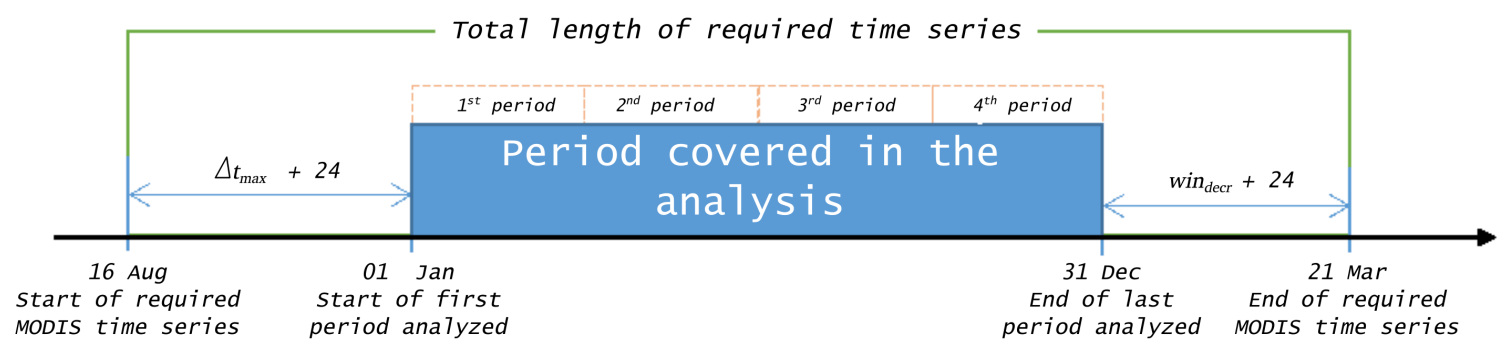

Figure 2: Schematic representation of input data requirements for a common analysis scenario: analysis conducted on a solar year, considering four equally long periods (the 24 additional days included at the beginning and end of the time series are required to accommodate the edges of the Savitzky-Golay window)

This work is licensed under a Creative Commons "Attribution-NonCommercialNoDerivatives 4.0 International" license. 
Pre-print, submitted for publication to Remote Sensing of Environment. The final approved manuscript is available at 10.1016/j.rse.2017.03.029

\section{Materials and methods}

\subsection{Case studies and datasets}

PhenoRice was applied in three different case study areas in Italy, India and the Philippines (Figure 3) to demonstrate its ability to correctly identify the main rice cultivation areas and to accurately estimate crop establishment and flowering dates in different environments and management conditions. These riceproducing areas were selected for two reasons. Firstly, they represent some of the most common rice production situations (Dawe et al., 2010). They are characterised by different climates (temperate and tropical in dry and wet season), different rice cropping methods (i.e., direct seeding in Italy, transplanting in India and Philippines) and different dominant rice crop intensities (rice-fallow in Italy, rice-other in India and rice-rice in Philippines). Secondly, comparable, high-quality and high spatial resolution reference data (based on remote sensing and field observations) for rice crop area and establishment dates were available for each site.

\subsubsection{Case Study 1: Northern Italy (ITA)}

The first case study area is located in the Po River alluvial plain in Northern Italy and covers the main Italian rice cultivation area (Bocchi et al., 2003). The rice area is around 210,000 ha and accounts for $90 \%$ of paddy rice cultivation in Italy and about $50 \%$ of total European rice production (FAO, 2016), making it the most important rice growing area in Europe. Climate is classified as subcontinental temperate, with average annual temperature of $12-14{ }^{\circ} \mathrm{C}$ and rainfall ranging from 600 to $1,400 \mathrm{~mm} \mathrm{y}^{-1}$. Rice is cultivated in irrigated conditions and the crop is established by seeding, either broadcast on submerged soils or directly in dry soils (the latter particularly in South-eastern areas) that are periodically irrigated until the unfolding of 2-4 leaves and continuously flooded thereafter.

Depending on the variety, rice is generally planted between early/mid-April and late May, and harvested in October. The area is located at the northern limit of the natural rice cultivation zone and is characterised by low temperature at the extremities of the crop cycle, irregular solar radiation and harvests frequently hindered by rain. Specific varieties for temperate climate have been bred, with very good cold tolerance at all growth stages and good resistance to the main pests and diseases of the region (GRiSP (Global Rice Science Partnership), 2016). Both Indica and Japonica group varieties are cultivated with either a medium (120-130 days; e.g. Gladio, Thaibonet, Selenio, Loto, etc.) or long growing cycle (> 150 days; e.g. Carnaroli, Volano, Baldo, etc.) (For details, see Table 1 in Boschetti et al. (2009) and Confalonieri and Bocchi (2005)). The average farm size is about 50 ha, usually divided into relatively small fields to better manage the water presence, to cultivate different variety for different markets request and to minimize

This work is licensed under a Creative Commons "Attribution-NonCommercialNoDerivatives 4.0 International" license. 
Pre-print, submitted for publication to Remote Sensing of Environment. The final approved manuscript is available at $10.1016 /$ j.rse.2017.03.029



Figure 3: Location and main characteristics of the three case study areas

potential negative seasonal effects (CREA, 2015; Ente Nazionale Risi, 2016). Within the study area, field size range from 0.7 to 7 ha, with an average of around 3 ha.

Validation datasets for the ITA study site came from two sources. A reference rice map was created on the basis of 10 and $20 \mathrm{~m}$ spatial resolution land cover maps provided by the Lombardy (ERSAF, 2013) and Piedmont (Regione Piemonte, 2011) regional authorities. In both maps, information about the location of rice areas was derived from annual official declarations provided by farmers about the crop cultivated in each of their parcels. Crop establishment date validation data were derived from weekly field observations

This work is licensed under a Creative Commons "Attribution-NonCommercialNoDerivatives 4.0 International" license. 
Pre-print, submitted for publication to Remote Sensing of Environment. The final approved manuscript is available at 10.1016/j.rse.2017.03.029

conducted in 2013 within six study sites of around 1000 hectares each, located in the provinces of Milano, Pavia and Novara (see Ranghetti et al. (2016) for details). Field surveys were conducted in the different sites from the $15^{\text {th }}$ of April (start of flooding) to the $7^{\text {th }}$ of July 2013 (around maximum tillering) and the field condition and the presence/absence of emerged rice crops in each rice field was recorded. The sowing date of each field was then estimated as the mid-point between the date of the last survey with no visible rice plants and the first survey with visible rice plants, minus 10 days (to account for the typical delay between sowing and emergence for Italian rice varieties).

\subsubsection{Case Study 2: Cauvery delta - India (IND)}

The second study area is located in the Cauvery delta of Tamil Nadu state in south-eastern India. This area is known as the "Rice Bowl" of Tamil Nadu and is part of the "Granary of South India", as it contains the rice growing districts of Ariyalur, Nagapattinam, Thanjavur and Thiruvarur that form the major source of food grain supply of the state. Around 520,000 ha of rice are grown in these four districts which represents $30 \%$ of the state total and rice is by far the most dominant crop, followed by pulses. Climate is classified as tropical savanna, with an average temperature around $29^{\circ} \mathrm{C}$ and average rainfall around $938 \mathrm{~mm}$, mostly concentrated in the June-September (South-west monsoon) and October-December (North-east monsoon) periods.

Rice is mostly cultivated in irrigated conditions and crop establishment is conducted mostly by transplanting with some direct seeding. A semi dry system is practiced in some parts of Thiruvarur where rice is seeded in ploughed dry soils, with water applied later in the season from irrigation or monsoon rains. The main rice cultivating period is the samba season, running from August to December with a late samba season or thaladi season from October to January. Most areas are characterised by a single rice season where medium- and long-duration (from 135 to 160 days) varieties are typical (e.g., CR1009, BPT5204 and ADT (R) 50). Other crops such as pulses are grown on residual moisture between January and March and these rice-pulse systems are the dominant cropping system in the delta. Rice can be grown in two other minor seasons; the navarai (from January/February to April/May) and kuruvai (from June/July to September/October) seasons when short duration varieties are grown, hence, rice-rice, rice-pulse-rice and rice-rice-rice systems are also present but are limited to small areas where there is sufficient irrigation. The latest agricultural census of 2010-2011 showed that the average size of land holdings were 0.58 ha, 0.86 ha, 0.72 ha and 0.92 ha in Ariyalur, Nagapattinam, Thanjavur and Thiruvarur respectively, with a state wide average of 0.80 ha (Department of Evaluation and Applied Research (DEAR), 2014).

Validation datasets available for the IND study area are based on $3 \mathrm{~m}$ resolution maps of rice area and

This work is licensed under a Creative Commons "Attribution-NonCommercialNoDerivatives 4.0 International" license. 
Pre-print, submitted for publication to Remote Sensing of Environment. The final approved manuscript is available at 10.1016/j.rse.2017.03.029

crop establishment dates for the samba season, covering an area of about 160000 ha in the delta region, based on an analysis of multi-temporal COSMO-SkyMed (CSK) X-band SAR (Synthetic Aperture Radar) Single Look Complex (SLC) data obtained from the Italian Space Agency (ASI/e-GEOS). A total of 9 images acquired at 16-day interval between 13/08/2013 and 26/12/2013 were used for both rice crop detection and crop establishment date estimation, following the method described in Pazhanivelan et al. (2015) and Nelson et al. (2014). Validation of the rice area map against field observations resulted in an overall accuracy $91 \%$, with a kappa coefficient of 0.73 .

\subsubsection{Case Study 3: Nueva Ecija and Pangasinan - Philippines (PHL)}

The third study area is within the provinces of Nueva Ecija and Pangasinan in Central Luzon, Philippines. These are respectively the first and third largest rice producing provinces in the country, mainly due to the highly suitable alluvial plains in both provinces. The climate in Nueva Ecija and Pangasinan has two pronounced seasons, dry (DS) from November to April and wet (WS) for the rest of the year, with an average annual temperature of around $27^{\circ} \mathrm{C}$ and average annual rainfall of around $1900 \mathrm{~mm}$.

About $88 \%$ of the rice area in Nueva Ecija is irrigated whereas in Pangasinan, it is only about $69 \%$. Most areas are characterised by a double rice crop season due to the extensive irrigation systems. More area is planted to rice in the WS, than the DS since rice is also grown in rainfed conditions in the WS (WS rice area in Nueva Ecija and Pangasinan $\approx 357,430$ ha; DS rice areas in Nueva Ecija and Pangasinan $\approx 211,103$ ha (Philippines Statistics Authority, 2016). In the WS, rice is generally planted in June/July and harvested in September/October, while in the DS it is planted in December/January and harvested in April. Most rice farmers practice direct-seeding during the DS and transplanting in the WS. Some areas of the irrigation system, however, report three crops per year, while the smaller rainfed areas can grow only one rice season in the WS. The main cultivated varieties are medium duration (about 110-120 days) such as NSIC Rc 222 (Laborte et al., 2015). The area is dominated by rice and farms are relatively small. A survey of 95 farm households in Central Luzon in 2011-2012 showed that the average farm size was 1.94 ha, with each farm averaging 1.22 ha and 1.32 ha of rice planted in the wet and dry seasons respectively (Moya et al., 2015).

Validation datasets for the PHL study area were derived from $18.5 \mathrm{~m}$ (WS) and 30m (DS) resolution maps of rice area and crop establishment dates for Nueva Ecija and Pangasinan based on an analysis of multitemporal COSMO-SkyMed (CSK) X-band SAR ScanSAR Huge Region imagery obtained from the Italian Space Agency (ASI/e-GEOS), and Terra SAR-X (TSX) ScanSAR imagery. Seven CSK images acquired at 16-day interval between 06/12/2012 and 13/04/2013 and 10 TSX images acquired at 11-day interval between 25/05/2013 and 23/09/2013 (although with a one-month acquisition gap in August) were used for rice crop

This work is licensed under a Creative Commons "Attribution-NonCommercialNoDerivatives 4.0 International" license. 
Pre-print, submitted for publication to Remote Sensing of Environment. The final approved manuscript is available at 10.1016/j.rse.2017.03.029

detection and rice crop establishment date estimation in the two seasons. Validation of the rice crop map against field observations revealed an overall accuracy of $90 \%$, with a kappa coefficient of 0.72 in detecting areas cultivated to rice in at least one of the seasons. Validation of the crop establishment dates for the DS season showed a strong relationship between the TSX-derived dates and the field-observed transplanting dates $\left(r^{2}=0.87\right.$; Root Mean Square Error $(R M S E=9$ days - Asilo et al. (2014)). More detailed information about the datasets used for the validation of crop establishment is reported in Supplementary materials Table S2.

\subsection{Data processing}

PhenoRice was applied in the three case study areas for the rice seasons for which validation datasets described in Section 2 were available, that is 2013 in ITA, 2013-2014 IND and 2012-2013 in PHL. To verify its overall flexibility in coping with different rice cultivation schemes only small changes were made to the algorithms' parameters for the three cases. The main changes were the adjustment of the starting point of the four analysed trimesters to facilitate detection of the main rice cultivation seasons, and the use of a slightly higher $E V I_{m_{i n} \text { th }}$ in IND and PHL. Adjusting the time periods according to study area allowed for a more meaningful analysis, since considering a "fixed" January to December time frame would have led to "winter" rice seasons in PHL and IND being artificially split between two different calendar years of analysis. By reasonably anticipating the start of the first period, it was possible to correctly detect all rice seasons for which harvesting occurred within the same "rice cultivation year". The adjustment of $E V I_{m i n \_t h}$ was aimed at improving rice detection in sites where a second/third rice crop was present and where rainfed rice was known to be present (Table 2).

Table 2: PhenoRice processing parameters used in the three case study areas

\begin{tabular}{|c|c|c|c|}
\hline & ITA & IND & PHL \\
\hline Year & 2013 & $2013-2014$ & $2012-2013$ \\
\hline Periods & $\begin{array}{c}01 / 01 / 12-31 / 03 / 1301 / 04 / 13 \\
-30 / 06 / 1301 / 07 / 13- \\
30 / 09 / 1301 / 10 / 13-31 / 12 / 13\end{array}$ & $\begin{array}{c}01 / 10 / 13-31 / 12 / 1301 / 01 / 14 \\
-31 / 03 / 1401 / 04 / 14- \\
30 / 06 / 1401 / 07 / 14-30 / 09 / 14\end{array}$ & $\begin{array}{c}01 / 12 / 12-28 / 02 / 1301 / 03 / 13 \\
-30 / 05 / 1301 / 06 / 13- \\
30 / 08 / 1301 / 09 / 13-31 / 10 / 13\end{array}$ \\
\hline$E V I_{\text {max_th }}$ & 0.4 & 0.4 & 0.4 \\
\hline$\Delta t_{\min }[$ days $]$ & 40 & 40 & 40 \\
\hline$\Delta t_{\max [\mathrm{days}]}$ & 114 & 114 & 114 \\
\hline$L S T_{t h\left[^{\circ} \mathrm{C}\right]}$ & 15 & 15 & 15 \\
\hline$E V I_{m i n_{-} t h}$ & 0.25 & 0.3 & 0.3 \\
\hline win $_{f l \text { [days }]}$ & 16 & 16 & 16 \\
\hline win $_{\text {decr [days] }}$ & 80 & 80 & 80 \\
\hline$d_{e c r_{t h}[\%]}$ & 50 & 50 & 50 \\
\hline
\end{tabular}

A simple mask derived by combining publicly available datasets was used in the three areas. In particular,

This work is licensed under a Creative Commons "Attribution-NonCommercialNoDerivatives 4.0 International" license. 
Pre-print, submitted for publication to Remote Sensing of Environment. The final approved manuscript is available at 10.1016/j.rse.2017.03.029

the Global Water/Land mask (http://glcf.umd.edu/data/watermask/) was used to mask out seas and water bodies and the Shuttle Radar Topography Mission (SRTM) Digital Elevation Model (DEM) product at $90 \mathrm{~m}$ spatial resolution was used to mask out areas above $2000 \mathrm{~m}$ a.s.l. and rugged/highly sloped terrains. This slope criterion was achieved by setting a threshold on the standard deviation of elevation within a $5 \times 5$ kernel. The mask reduced processing time and excluded areas with very low probabilities of belonging to rice cultivations.

Figure 4 shows exemplar plots of PhenoRice estimates of rice phenological dates (crop establishment and flowering are shown by the orange and green dotted lines respectively) based on the temporal patterns of NDFI (blue) and smoothed EVI (red) for different cropping systems in the three study areas. It also shows the variability in cropping systems across and within the sites. The ITA case shows one rice season from June to October and low EVI in the rest of the season suggesting bare soil, flooded fields or fallow conditions. Four examples are given in IND (from top to bottom): i) the samba rice season with rice grown from September to January and fallow fields for the rest of the year; ii) the samba rice season followed by another crop, probably pulses (the most dominant cropping system in the region); iii) two rice crops, samba/thaladi (Oct-Jan) and kuruvai (May-Aug), possibly separated by a pulse crop (Feb-Apr), and iv) three rice seasons; samba/thaladi, late navarai and kuruvai. These last two examples occur more rarely. Four examples are also given in the PHL site: i) a single rice season in the DS with no crop in the WS due to excessive stagnant water (strong NDFI signal); ii) a single rice season in the WS preceded by another crop (possibly maize or vegetables) in the DS, iii) a double rice season, which is the dominant cropping system (rice stubble/weeds are evident after the DS rice crop); iv) a triple rice season where an early and late WS crops are present as well as a DS crop (Asilo et al., 2014).

\subsection{Post-processing and validation}

\subsubsection{Assessment of PhenoRice rice detection accuracy}

First we assessed PhenoRice's performance in correctly identifying rice cultivated areas using the high resolution maps available in the three areas (section 3.1). Although PhenoRice is not per-se an area estimation method, it must correctly identify a representative sample of the rice cultivated area to allow accurate characterization of seasonality and cropping intensity of the analyzed rice systems. We performed a "local product accuracy" assessment, and a "regional product accuracy and precision" assessment following the validation of coarse resolution burnt area maps method proposed by Roy and Boschetti (2009).

Local product accuracy was assessed by first resampling the MODIS-derived rice maps to the resolution and projection of the available reference maps, and then evaluating the accuracy using a standard confusion

This work is licensed under a Creative Commons "Attribution-NonCommercialNoDerivatives 4.0 International" license. 
Pre-print, submitted for publication to Remote Sensing of Environment. The final approved manuscript is available at 10.1016/j.rse.2017.03.029
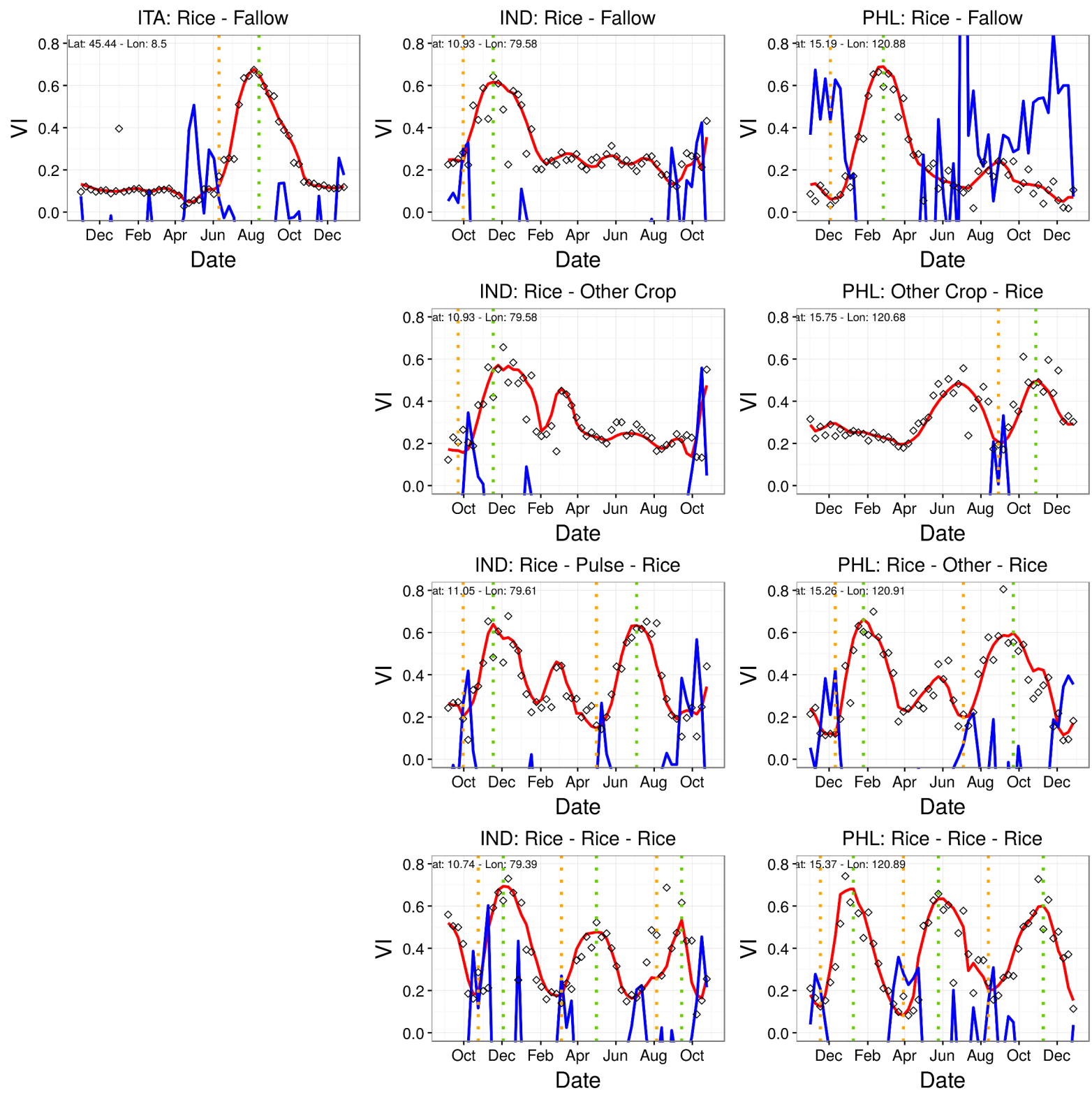

- Crop Establishment $=$ - Crop Flowering $\diamond$ EVI - Raw — EVI - Smoothed — NDFI

Figure 4: Example of PhenoRice results for example pixels of the three Case Study areas.

matrix approach, thus evaluating metrics such as the overall accuracy $(\mathrm{OA})$ and the commission and omission errors ( $\mathrm{CE}$ and $\mathrm{OE})$ for the rice class. Additionally, an analysis was performed to evaluate the effect of target fragmentation/homogeneity on PhenoRice detection. This was accomplished by evaluating the algorithm's rice detection rate as a function of rice fractional cover (from the high resolution maps) within the MODIS pixels.

This work is licensed under a Creative Commons "Attribution-NonCommercialNoDerivatives 4.0 International" license. 
Pre-print, submitted for publication to Remote Sensing of Environment. The final approved manuscript is available at 10.1016/j.rse.2017.03.029

The regional product accuracy assessment was conducted by overlaying a 9 x 9 MODIS pixel fishnet (approximately $2 \times 2 \mathrm{~km}$ ) over the study site and recording the rice area estimated by MODIS and the high resolution maps within each grid cell. The relationship between the two rice area estimates was evaluated with standard linear regression analysis metrics (e.g., slope and intercept of the regression, $r^{2}, R M S E$ ). This assessment method reduces the effect of factors such as the difference in resolution between the two data sets, low resolution bias (Boschetti et al., 2004), coregistration problems and point spread function (PSF) effects (Duveiller et al., 2011). Given that PhenoRice aims to detect a representative sample of the rice growing area as opposed to a complete enumeration of the rice area, this regional approach is considered to be a more robust and appropriate assessment than local product accuracy for assessing PhenoRice's ability to detect a representative sample of the rice growing area on a regional scale.

\subsubsection{Assessment of PhenoRice's estimation of crop establishment and flowering dates}

The accuracy of crop establishment date detection was analysed on the basis of both expert knowledge about the cropping systems under analysis, and comparison with available reference data. In particular, a qualitative evaluation was first of all performed by analysing PhenoRice's estimates with reference to the existing knowledge about the characteristics of each study area (e.g., typical crop calendars and crop intensity as reported in section 3.1). A quantitative analysis of the accuracy of the rice crop establishment estimates was then conducted by comparing the PhenoRice date estimates to the high resolution crop establishment maps (section 3.1), both averaged on the $2 \times 2 \mathrm{~km}$ grid to reduce the effects of the different resolution of the maps on accuracy evaluation.

In the second analysis, aggregation of the high resolution maps to the $2 \times 2 \mathrm{~km}$ grids was conducted considering only high resolution pixels falling within MODIS pixels for which rice fractional cover was greater than $75 \%$. This allowed us to account for the unavoidable lower performance of PhenoRice in rice detection in fragmented rice cultivation areas. In the case of PHL and IND we only considered MODIS pixels with estimated establishment dates that fell within the range of the dates that could be derived from the SAR time series for each site. This avoided the inclusion of areas sown in periods outside the SAR time series, ensuring comparable temporal information from both sources. A regression analysis was then performed and standard accuracy metrics $\left(r^{2}\right.$, Mean Error $(M E)$, Mean Absolute Error $(M A E)$ and $\left.R M S E\right)$ were computed to assess the precision and accuracy of MODIS date of establishment estimates. In PHL, the analysis was conducted separately for DS and WS, whereas only one rice season was considered in the ITA and IND sites.

This work is licensed under a Creative Commons "Attribution-NonCommercialNoDerivatives 4.0 International" license. 
Pre-print, submitted for publication to Remote Sensing of Environment. The final approved manuscript is available at 10.1016/j.rse.2017.03.029

\section{Results and discussion}

\subsection{Detection of rice cultivated area and number of rice seasons}

The number of rice seasons detected for each pixel (Figure 5) highlights the differences in rice crop intensity and their spatial patterns between the three sites. Across all three sites there was a good correspondence between the spatial patterns of the observed and expected dominant cropping systems.

In ITA, rice is produced once per year in the summer season. In IND, most of the rice growing area has a single crop of rice per year, with some double rice areas mainly along the Kollidam River, and a few small patches of triple rice area concentrated in Thanjavur wherever ground water resources are plentiful. In PHL, double rice is the dominant cropping system, specifically in the irrigated areas of Nueva Ecija province. Single rice areas were more prominent in Pangasinan where a higher proportion of rice areas are rainfed. The algorithm detected triple rice areas in Cabanatuan municipality and this was confirmed by municipal agricultural officers in the area where a "Quick Turnaround" program of the National Irrigation Administration has been ongoing since 2012, meaning that no fallow period is implemented. Some farmers in the municipality also practiced ratooning where the rice stubble is left standing to sprout or ratoon and produce another smaller harvest in $65 \%$ of the time of the main crop and with less labour (personal communication, IRRI 2016).
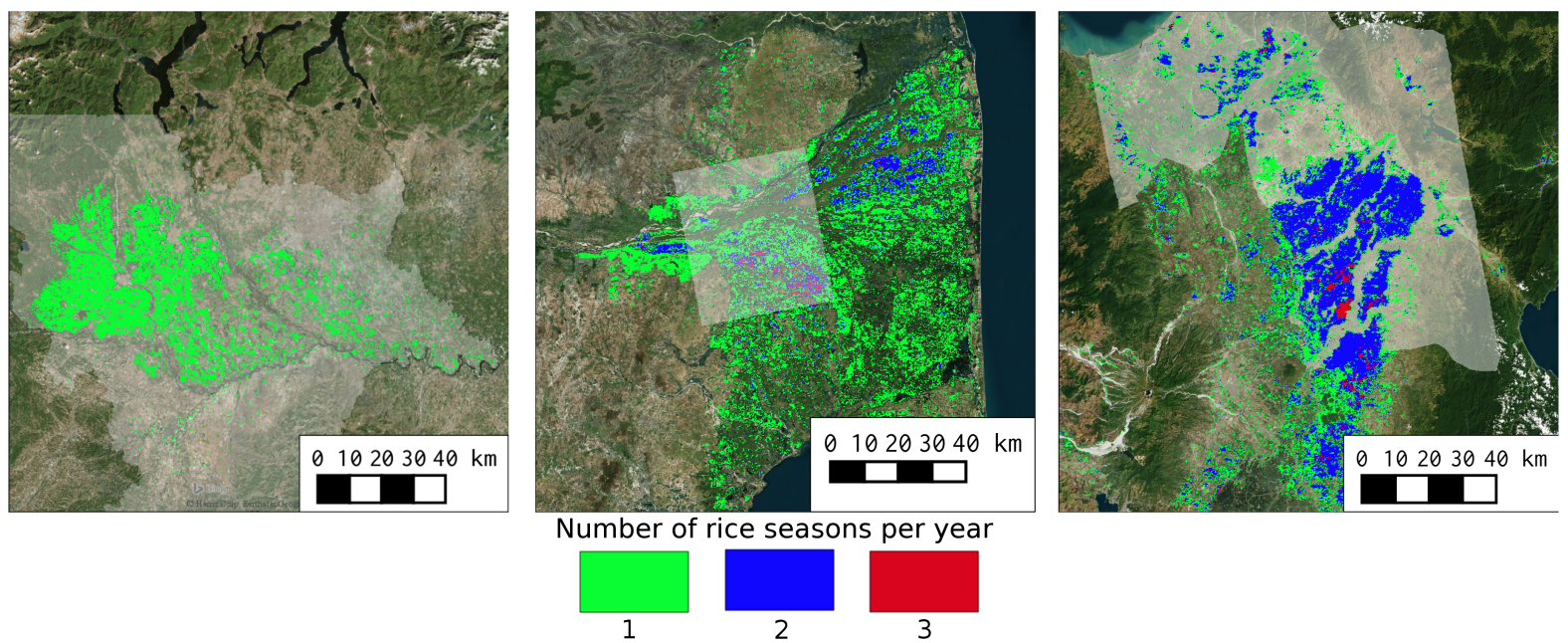

Figure 5: Rice detection in the three case study areas: ITA (left), IND (centre) and PHL (right). Single, double and triple seasons are represented in green, blue and red respectively. Grey areas highlight the extent of the high resolution validation map.

\subsubsection{Analysis of rice detection accuracy}

Table 3 reports the results of the analysis of PhenoRice local product accuracy analysis for rice mapping (section 3.3.1) for the three case study areas. Overall Accuracy (OA) was greater than $80 \%$ for all test cases

This work is licensed under a Creative Commons "Attribution-NonCommercialNoDerivatives 4.0 International" license. 
Pre-print, submitted for publication to Remote Sensing of Environment. The final approved manuscript is available at 10.1016/j.rse.2017.03.029

except IND (71\%), with omission errors for the rice class in the range of 25 to $40 \%$, and commission errors in the range of 20 to $35 \%$.

Table 3: Results of PhenoRice local accuracy for rice detection. Overall (OA), Producer's (PA) and User's Accuracy (UA) were derived from comparison of the HR reference maps with PhenoRice maps resampled to the same resolution.

\begin{tabular}{|c|c|c|c|c|}
\hline & $\begin{array}{l}\text { ITA } \\
\text { Summer season }\end{array}$ & $\begin{array}{l}\text { IND } \\
\text { Samba season }\end{array}$ & $\begin{array}{l}\text { PHL } \\
\text { Wet season }\end{array}$ & Dry season \\
\hline Overall Accuracy & 80 & 71 & 80 & 80 \\
\hline Producer's Accuracy rice & 70 & 60 & 60 & 75 \\
\hline User's Accuracy rice & 65 & 80 & 75 & 65 \\
\hline
\end{tabular}

Although these errors may appear high, they need to be evaluated in the context of using moderate resolution MODIS images in these study sites. There is an unavoidable underestimation of area in fragmented agro-ecosystems due to the mixed pixel effect causing contamination of the "rice signal" and therefore a reduction in detection capabilities. There is also a tendency towards overestimation in the main rice areas, due to the fact that a MODIS-based analysis cannot recognize small non-rice areas (low resolution bias - Boschetti et al. (2004)). These results highlight the challenge of assessing the accuracy of moderate resolution maps in rice growing areas as well as in making direct comparison between maps derived from high and coarse resolution satellite imagery.

A better understanding of the algorithm's performance in relation to target characteristics can be derived from the results of the analysis of $i$ ) the algorithm's detection rate as a function of rice fractional cover within MODIS pixels (see Figure S1 for details) together with ii) the analysis of Pareto boundaries (Boschetti et al., 2004) for the four seasons across the three study sites as an indicator of site fragmentation (Leroux et al., 2014). The analysis shows that while the omission error for mixed rice-non rice pixels was quite high, and higher still for the fragmented IND site, (see Figure S2 for details), the algorithm detection performance was above $70 \%$ in pixels with rice fractional cover above $70 \%$. This suggests that PhenoRice is able to identify the main rice cultivation areas, which is essential for selecting a representative sample of the rice systems and subsequently analysing their cropping dynamics.

A more focused and spatially explicit analysis of PhenoRice's rice detection capabilities at a regional scale can be seen in the regional product accuracy assessment (Figure 6).

There are strong, positive, linear relationships between the high resolution map rice area and the PhenoRice detected rice area in all four cases $\left(r^{2}\right.$ between 0.75 and 0.92$)$. The slope of the linear regression shows an underestimation of between 20 and 30\%, with the exception of the dry season in PHL, where PhenoRice tends to overestimate rice area.

This work is licensed under a Creative Commons "Attribution-NonCommercialNoDerivatives 4.0 International" license. 
Pre-print, submitted for publication to Remote Sensing of Environment. The final approved manuscript is available at 10.1016/j.rse.2017.03.029

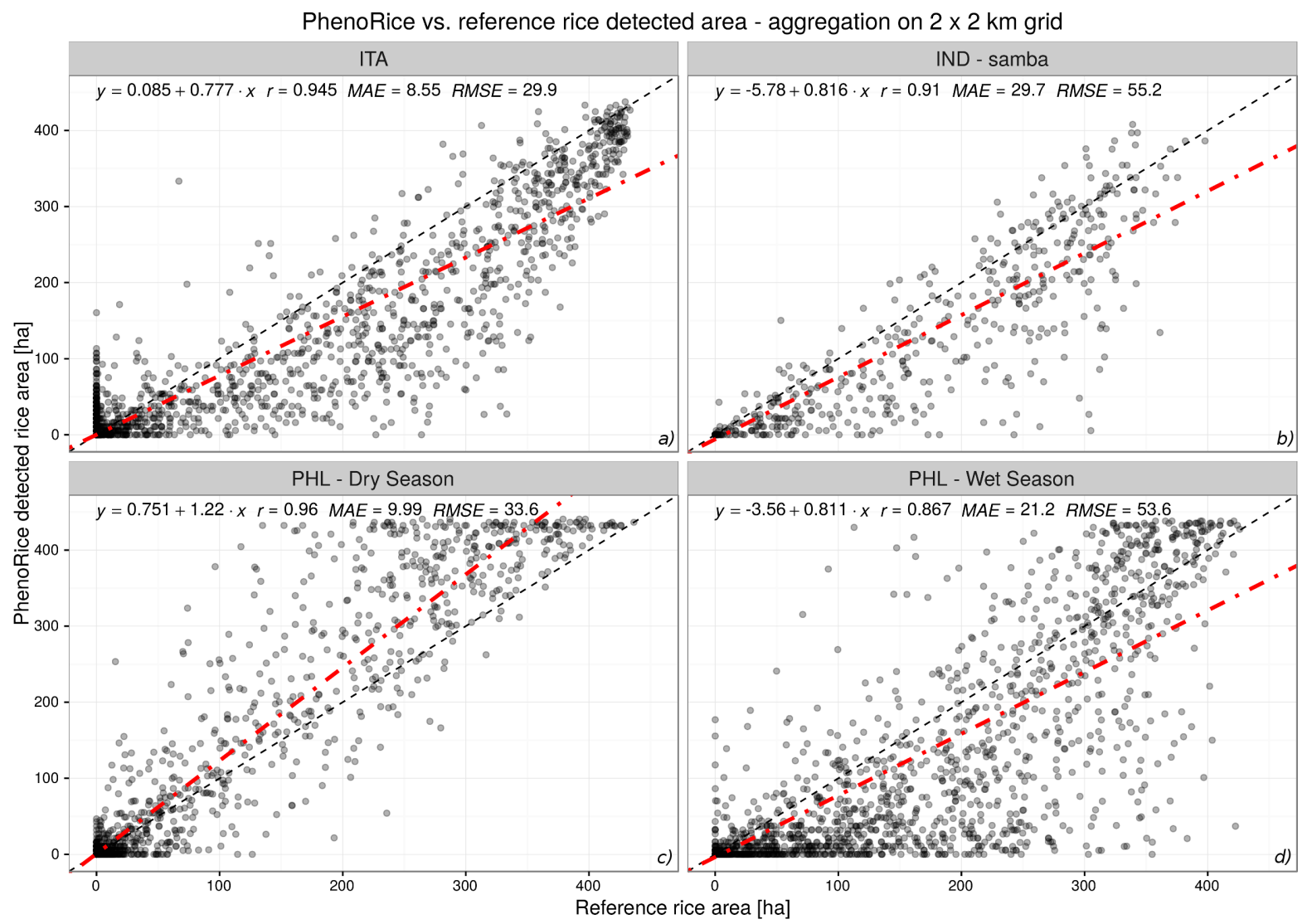

Figure 6: Comparison between reference and PhenoRice rice area, aggregated on a $2 \times 2 \mathrm{~km}$ regular grid. ITA (a), IND (b), PHL - wet season (c) and PHL - dry season (d)

This work is licensed under a Creative Commons "Attribution-NonCommercialNoDerivatives 4.0 International" license. 
Pre-print, submitted for publication to Remote Sensing of Environment. The final approved manuscript is available at 10.1016/j.rse.2017.03.029

In ITA, the rice detection performance was very good $\left(r^{2}=0.89\right)$. This is due to the high quality of the MODIS signal (low levels of cloud contamination, see Figure S3) in summer over the Po Plain, the clear contrast between rice flooded fields and the surrounding environment in spring, and to the relatively low fragmentation of this intensive rice cultivated area, as confirmed by the Pareto boundary analysis (see Figure S2). Underestimation of rice area occurred mainly in the Eastern part of the study area (Pavia province), where sowing of rice in dry-soil conditions is becoming a common practice (up to $30 \%$ of the area in 2015 - Ente Nazionale Risi (2016)), and where a more fragmented agro-landscape is typical due to the higher presence of other summer crops such as corn and soybean. Some overestimation occurred in the north-eastern part (Milano and Lodi provinces) possibly due to the atypically strong and continuous rain events in the 2013 spring season during the sowing period (Camera di Commercio di Pavia, 2013). These anomalous rain events delayed rice sowing (Boschetti et al. (2015a); see Figure S6 for details) and led to flooding of corn fields that could have been misdetected as rice, thus increasing the commission error.

Rice detection performance in IND showed an underestimation of the area. This relates to the characteristics of the case study area, which has higher fragmentation than ITA and PHL (see Figure S2). There are few samples in the reference data set for IND where the entire $2 \times 2 \mathrm{~km}$ cell is fully covered by rice (16\% and $2 \%$ for rice presence greater than $90 \%$ and $100 \%$ respectively).

Results in the PHL study area showed contrasting results in the DS and WS. In the DS, PhenoRice performed very well in identifying the homogeneous irrigated rice areas thanks to the strong flooding signal. This good performance can be attributed to the medium and large scale irrigation systems and since there is no natural flooding and little moisture due to rain in the surrounding non-irrigated areas. Thus there is a higher contrast between neighbouring wet and dry areas (Gond et al., 2004). There is also very little fragmentation in the PHL-DS (Figure S2) and levels of cloud contamination are typically low (Figure S3). Detection of rice areas in the WS was affected by persistent cloud cover during the monsoon which reduced the overall quality of the MODIS data (Figure S3). In addition, some rice areas are grown under rainfed conditions (in particular in Pangasinan province) which increased the difficulty in detecting the "rice signal" leading to underestimation (Figure 6).

In summary, these results confirm that PhenoRice performs satisfactorily in accurately identifying a representative and robust sample of the rice-cultivated area under different environmental and management conditions, including tropical areas where cloud contamination impacts on data quality. The performance of the algorithm also matched expectations given the prior, expert local knowledge of the rice systems.

This work is licensed under a Creative Commons "Attribution-NonCommercialNoDerivatives 4.0 International" license. 
Pre-print, submitted for publication to Remote Sensing of Environment. The final approved manuscript is available at 10.1016/j.rse.2017.03.029

\subsection{Analysis of spatially-explicit information on crop dynamics}

Having demonstrated that PhenoRice has captured a representative sample of pixels within the rice growing areas, the EVI and NDFI time series of each rice pixel were analysed to estimate the timing of rice crop establishment (sowing or transplanting).

\subsubsection{Crop establishment mapping and validation}

Figure 7 shows the maps of crop establishment dates (sowing in ITA and sowing/transplanting in IND and PHL sites) for the first and second detected seasons. The maps highlight clear spatial patterns in rice crop practices in the three study areas that are in agreement with the known crop practices and variety distribution.

In ITA (Figure 7a), sowing dates typically exhibit a north-west to south-east gradient due to differences both in water availability and release dates (Ranghetti et al., 2016), and in cultivated varieties. While the western part is dominated by traditional varieties with earlier sowing, the eastern part is characterised by shorter duration varieties that are sown up to the end of May (Boschetti et al., 2009). In IND, the crop establishment period of the main season (Figure 7b) ranges from August until October representing the samba and late-samba (thaladi) seasons, respectively. Areas with two rice seasons show the second (navarai) season starting mainly in February following the first one in October (Figure 7c). Areas with three rice seasons are too small to describe reliably. In PHL, crop establishment in the DS (Figure 7d) shows two clear spatial clusters with transplanting occurring earlier in the south (December) than in the north (January - February). This is reversed in the WS where crop establishment ranges between June and August (Figure 7e). The identified spatial variability in DS was found to be directly related to the water release dates in the different irrigation zones of Nueva Ecjia and Pangasinan (IRRI personal communication, 2016 - data not shown).

Figure 8 provides a comparison between establishment dates estimated from PhenoRice and corresponding high-resolution maps (after aggregation to a $2 \times 2 \mathrm{~km}$ grid). The data from the three sites are ordered according to their date of occurrence between December 2012 and November 2013. Parameters from a linear regression analysis between PhenoRice dates and reference establishment dates are shown in the top left box (slope, intercept and $r^{2}$ ), as well as the estimation error metrics Mean Error $(M E)$ and Mean Absolute Error $(M A E)$. Overall the PhenoRice establishment dates for the three sites are in very close agreement with the reference data $\left(r^{2}=0.98, M E=4.07\right.$ days, $M A E=9.95$ days $)$ and the relationship between estimated and reference dates is statistically significant $(p<0.01)$.

Across all sites, $M A E$ was less than 10 days, with values below 6 days for ITA and PHL-DS, and around

This work is licensed under a Creative Commons "Attribution-NonCommercialNoDerivatives 4.0 International" license. 
Pre-print, submitted for publication to Remote Sensing of Environment. The final approved manuscript is available at $10.1016 /$ j.rse.2017.03.029

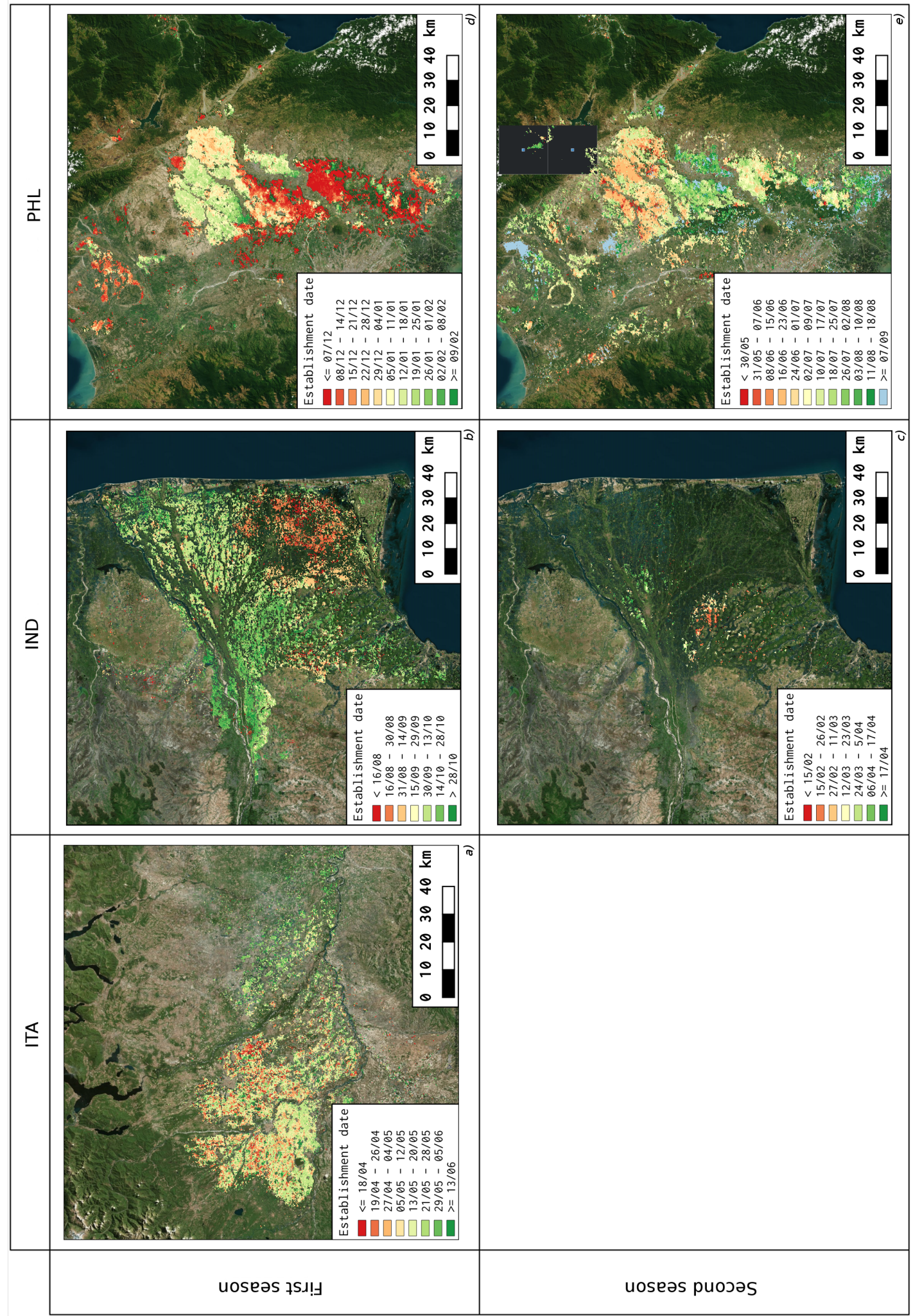

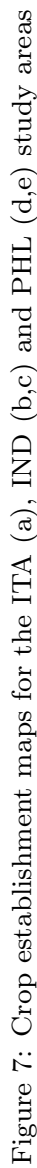

This work is licensed under a Creative Commons "Attribution-NonCommercialNoDerivatives 4.0 International" license. 
Pre-print, submitted for publication to Remote Sensing of Environment. The final approved manuscript is available at 10.1016/j.rse.2017.03.029

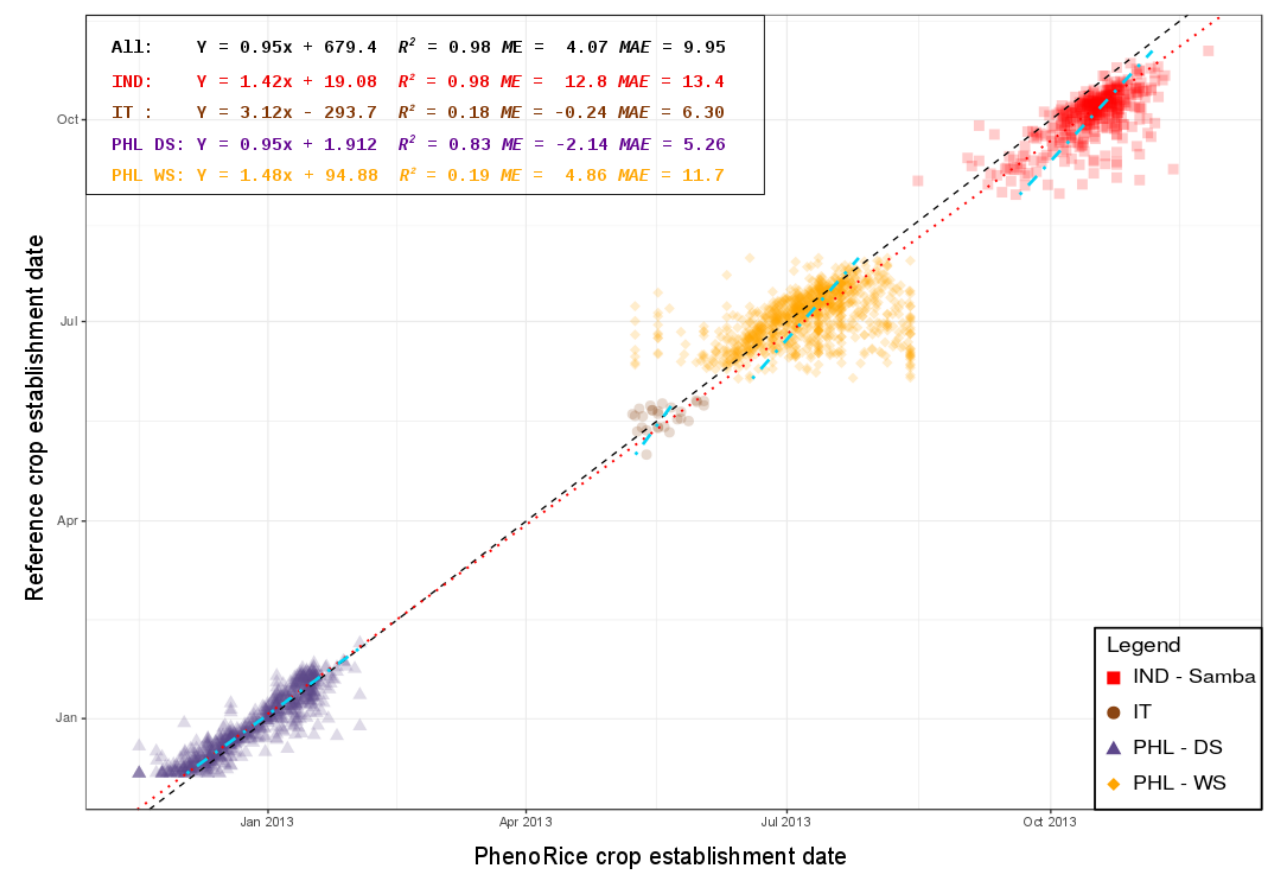

Figure 8: PhenoRice crop establishment dates vs reference crop establishment dates. Black and red dashed lines are the 1:1 and overall linear regression line. Dashed cyan lines are the linear regression lines for the different countries and seasons. Accuracy indicators are reported in the top left box in the form of parameters of the regression lines, $r^{2}$, mean $(M E)$ and mean absolute $(M A E)$ estimation errors.

12 days for IND and PHL-WS. This suggests a higher accuracy of PhenoRice in irrigated rice areas/seasons, where the flooding and subsequent rice growth signals are more clearly identifiable. Accuracy in rice areas with mixed rainfed/irrigated growing conditions such as IND and PHL-WS, where quality of the MODIS signal is also reduced by the frequently cloudy conditions (Figure S3), is lower although still satisfactory. Figure S4 shows a visual comparison of establishment date estimates between HR and PhenoRice maps in PHL for both dry and wet season.

Although our results are internally encouraging, we also made a qualitative external assessment against the few studies that compare crop establishment dates from moderate resolution remote sensing data and field observations. These studies consistently obtained similar or poorer results to the ones we report here. For example, Chumkesornkulkit et al. (2013) reported errors of less than 16 days, in the estimation of establishment dates for irrigated rice areas in Thailand, in $75 \%, 83 \%$ and $27 \%$ of cases for single, double and triple rice season respectively. Suwannachatkul et al. (2014) reported $M A E$ of around 12 days in the estimation of rice establishment dates for both irrigated and rainfed rice areas in Thailand. Sakamoto et al. (2005) reported $R M S E$ s of around 12 days in the estimation of establishment dates in Japan. In all three examples the analysis was carried out on one specific rice crop environment with fewer validation data

This work is licensed under a Creative Commons "Attribution-NonCommercialNoDerivatives 4.0 International" license. 
Pre-print, submitted for publication to Remote Sensing of Environment. The final approved manuscript is available at 10.1016/j.rse.2017.03.029
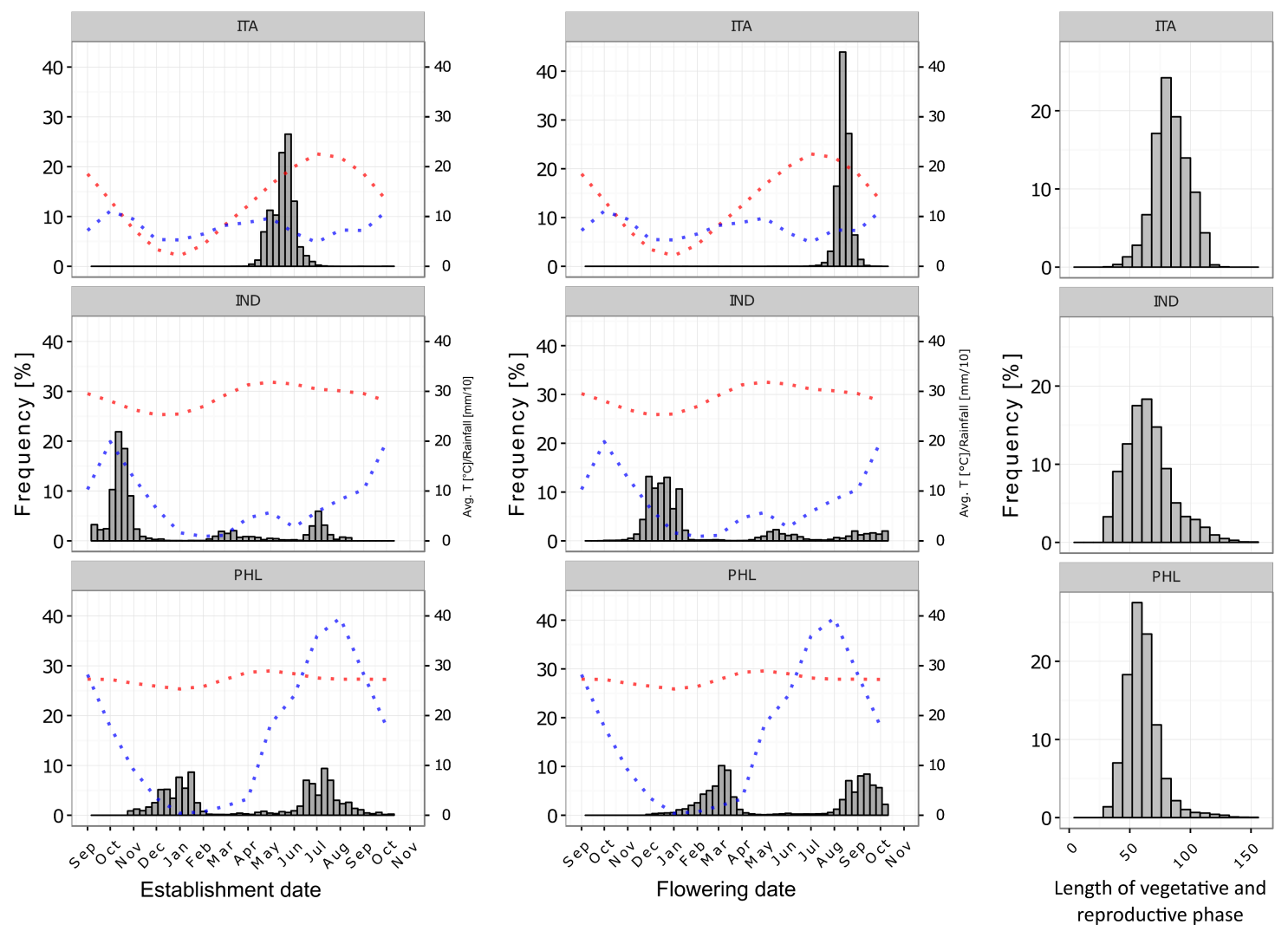

Figure 9: Distribution of crop establishment dates (left panel), flowering dates (centre panel) dates and the combined length of the vegetative and reproductive phases (sowing to flowering period - right panel) for ITA, IND and PHL (from top to bottom). Average air temperature (red dotted line) and average total monthly precipitation (blue dotted line) derived from WorldClim data are also shown in the left and centre panels.

points than our study. The ability of PhenoRice to perform at least as well as other studies across a range of environments suggests that PhenoRice has the potential to be applied over large extents for rice crop establishment date mapping.

\subsubsection{Analysis of rice crop dynamics in the study areas}

Figure 9 shows the frequency histograms of estimated crop establishment dates, flowering dates and the combined length of the vegetative and reproductive phases - from sowing/transplanting to flowering - as well as average monthly air temperature and precipitation derived from WorldClim data (Hijmans et al., 2005).

In ITA, a single summer crop signal is evident with a unimodal but broad distribution of establishment dates, $90 \%$ of which are between the middle of April and the end of May. The variability is mostly due to the cultivation of rice varieties with very different growth durations across the Piedmont (West) - Lombardy (East) area (from 120 to up to more than 160 days). Earlier sowing is commonly associated with traditional

This work is licensed under a Creative Commons "Attribution-NonCommercialNoDerivatives 4.0 International" license. 
Pre-print, submitted for publication to Remote Sensing of Environment. The final approved manuscript is available at 10.1016/j.rse.2017.03.029

Japonica long duration varieties (e.g., Carnaroli, Volano, etc.) while medium duration ones (e.g., Indica Gladio, Thaibonet, and Japonica Selenio, Loto) are sown in mid-late May. The flowering dates show a much narrower distribution, with $90 \%$ of the flowering dates occurring in a 20 days period between the end of July and the middle of August. This highlights how rice cultivation in Italy is planned to efficiently exploit the short favourable growth period for rice. Before April, the air temperature is too low for sowing. Similarly, low temperatures and solar radiation in late summer may hamper rice maturation. Farmers sow different varieties at different times so that peak flowering is reached around August, to take advantage of the best meteorological conditions for efficient grain filling (see additional analysis in Figure S4). Rice has a longer vegetative phase in this temperate climate than in the tropical sites (Figure 9 - right panel). In general, despite Italian varieties being selected for their adaptation to temperate climates, the low spring temperature means a slower growth of the rice plant (fewer growing degree days) and a longer season. Furthermore, the rice crop is direct seeded so plants are in the field for around 20 days longer than a transplanted rice seedling. Finally the Italian rice market and cuisine is still largely based on use of traditional longer duration varieties. This is a good example of how management practices and market preferences combine with climate to determine the local rice cultivation practices.

In IND, rice is established in up to three seasons, with peak establishment dates in October (samba/latesamba season), February (navarai season) and July (kuruvai season) due to the presence of favourable weather conditions for rice cultivation for the entire year. The frequency histograms show that the samba season is by far the largest of the three. Systems with two rice seasons show the occurrence of the second rice season mainly in February/March (Figure 8). The estimated combined length of the vegetative and reproductive phases in the samba season is in agreement with the known agro-practices and varieties. Medium and long-duration varieties, such as CR1009, BPT5204 and ADT(R)50, are mainly grown, with durations from 135 to 160 days though shorter duration varieties are also grown, especially where three crops of rice are grown per year (Nelson et al., 2014). The shorter length of vegetative season for IND (and PHL) with respect to ITA can be related to the transplanting of seedlings that are grown for different lengths of time in the nursery. Traditional varieties can be transplanted between 30 to 45 days after seeding while modern varieties can be transplanted within 15-25 days or less if mechanically transplanted.

The PHL site shows a bimodal distribution of establishment dates related to the two main rice seasons. The large spread of estimated dates within each season reflects the corresponding spatial variability of crop establishment dates. In particular, both WS and DS frequency histograms show two peaks corresponding to early and late establishment. DS sowing occurs between November and February with two clear peaks

This work is licensed under a Creative Commons "Attribution-NonCommercialNoDerivatives 4.0 International" license. 
Pre-print, submitted for publication to Remote Sensing of Environment. The final approved manuscript is available at 10.1016/j.rse.2017.03.029

in December and January. WS transplanting is between June and September with peaks in June and late July (see also Figure 6). The areas with three rice crops per year (see Figure 4) usually have an early DS (October-November) followed by a late DS/early WS establishment in April and finally a late WS establishment in August. The combined length of the vegetative and reproductive phases peaks at 60 to 70 days which is typical of commonly grown 110 to 120 day varieties that are transplanted as 20 day old seedlings. The growth cycle of a typically grown variety such as NSIC Rc 222 (an inbred variety with a duration of 114 days) can be broken down into transplanting of a 20 day old seedling, then 64 days to reach flowering and a further 30 days to reach maturity) (Laborte et al., 2015).

These results are encouraging and suggest the PhenoRice can provide accurate and representative estimates of crop establishment and flowering dates. These are useful and descriptive measures that can be used to directly characterize the observed rice cropping system (see also Figure S4). These date estimates are also vital inputs for crop growth simulation models, pest and disease models and other analyses that require spatio-temporal information on key crop development stages in order to estimate biomass availability, water use, yield and exposure to yield reducing stresses. Application of the algorithm to multiple years of MODIS data could reveal medium term (10-15 years) changes in establishment dates, inter-annual changes in cropping intensity, and changes in vegetative and reproductive phase length indicative of a shift to varieties with different durations and the impacts of atypical weather or water availability. In combination with weather and climate information, the same results could be used to suggest optimal establishment dates or season lengths to reduce the risk of exposure to abiotic stresses at key growth stages.

\subsection{PhenoRice advantages, limitations and suitability for within-season phenological monitoring 4.3.1. Factors influencing rice identification}

The analysis of Phenorice detection performance confirmed that cloud contamination, target fragmentation, the contrast between a flooded area and the surrounding environment and crop establishment practices can all influence rice identification capability. Although we do not consider these different factors independently, the diversity of situations in the case study sites allows us to draw some conclusions about algorithm robustness and applicability in other contexts.

As expected, cloud contamination in PHL-WS was pervasive between July and August, when up to $80 \%$ of pixels were cloudy for some acquisitions (Figure S3). Despite this, the results are still satisfactory and are comparable to other published methods for rice mapping (Gumma et al., 2011) or cropland maps produced from MODIS data (Leroux et al., 2014), and the crop establishment date is estimated with good accuracy $(M A E=11.7$ days $)$. Target fragmentation relates to the intrinsic limitation of moderate resolution data

This work is licensed under a Creative Commons "Attribution-NonCommercialNoDerivatives 4.0 International" license.

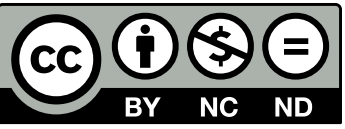


Pre-print, submitted for publication to Remote Sensing of Environment. The final approved manuscript is available at 10.1016/j.rse.2017.03.029

in land cover mapping. The regional validation revealed that the algorithm is able to capture the spatial pattern of crop presence and compared well against HR data sets, though the total area is underestimated, especially for IND. The Pareto boundary analysis (Figure S2), which has also been exploited in a similar manner by Leroux et al. (2014) and Waldner et al. (2015), confirmed that the IND case study site is more challenging and thus a high omission error should be expected. The PHL-DS and ITA sites have the best conditions: cloud contamination is very low; the rice area is homogeneous with respect to MODIS pixel size, and; in PHL-DS, the flooded fields show a strong contrast with the surrounding environment.

\subsubsection{Usability in other regions}

A limitation in the current implementation of PhenoRice is its reliance on the identification of flooded or saturated field conditions prior to crop establishment. These conditions are typical of irrigated and rainfed lowland rice systems, where the field is flooded before the crop is established and the soil continues to be flooded or saturated for much of the season. There are 93 million hectares of irrigated rice and 52 million hectares of rainfed lowland rice, and these account for more than $90 \%$ of global rice production. Other practices where we can expect little or no flooding signal, such as rainfed upland rice and "aerobic" rice, cover 15 million ha (less than 10\% of the global rice area - GRiSP (Global Rice Science Partnership) (2013), but their importance varies by region: in Central and West Africa, upland rice comprises about $35 \%$ of the total rice area (GRiSP (Global Rice Science Partnership), 2013); in the Cerrado region of Brazil, farmers grow aerobic rice on about 250,000 ha of flat lands (International Rice Research Institute (IRRI), 2016); in China, aerobic rice was estimated to cover 1 million ha in 2015 (Templeton and Bayot, 2011). Transplanting and wet seeding establishment are by far the most dominant methods of crop establishment, although dry seeding is prevalent in the USA, and in rainfed systems in parts of China and north west India. Dry seeding is also practiced traditionally in most Asian countries in rainfed upland ecosystems. This practice is also becoming more and more popular also in southern Europe, and in particular in the north of Italy (Ranghetti et al., 2016).

In general, we assume that PhenoRice is well suited to situations where rice is transplanted or wet seeded under irrigated or rainfed conditions, which accounts for the vast majority of rice growing areas. Performance can be degraded in rice growing areas where dry seeding is practiced, aerobic rice is grown, or where fields are sloping. These areas constitute a small percentage of the global rice area.

\subsubsection{Robustness of processing parameters and the need for local calibration}

The choice of processing parameters (Table 2) influences the ability of PhenoRice to accurately detect the rice seasons occurring within the spatial and temporal analysis window. Our results showed however that

This work is licensed under a Creative Commons "Attribution-NonCommercialNoDerivatives 4.0 International" license. 
Pre-print, submitted for publication to Remote Sensing of Environment. The final approved manuscript is available at 10.1016/j.rse.2017.03.029

the criteria used to identify the "rice signal" were stable across the three sites, with only a slight modification in $E V I_{\text {min_th }}$ required to help improve rice detection in rainfed or double/triple cropping areas. $E V I_{m i n \_t h}$ was set to a lower value in ITA since rice is sown in spring into wet fields that were left bare during winter. Some local knowledge of the rice growing environment can help therefore to guide threshold choice and the stability of these thresholds and their relation to management practices and environmental conditions should be further explored, but current results are promising for testing and implementation in other areas.

The choice of the most appropriate temporal windows used in the analysis can be also guided by local knowledge of the rice growing seasons in the different areas, or by referring to published rice crop calendars. However, we note that many published calendars do not include the minor growing seasons for a second or third rice crop, and efforts should be made to improve the spatial and temporal detail of published crop calendars. In this context PhenoRice can prove useful for better characterization of the spatial variability rice growing seasons in different areas of the world, providing, for example a better understanding of the potential impact of adverse meteorological conditions on rice production.

\subsubsection{PhenoRice usefulness and foreseen improvements}

PhenoRice is not designed as a crop mapping tool to retrieve cultivated area statistics, but as a tool to identify a representative and robust sample of rice cultivated pixels from which to extract accurate information on crop dynamics. This information can be an input to analyses of changes in cropping practices in time, or as inputs to crop modelling. Accurate rice area estimates require higher resolution remote sensing data such as ESA Sentinel 1, 2 or both combined. Both platforms provide imagery with pixel sizes that are smaller than or comparable to typical rice field sizes and have revisiting times that provide sufficient acquisitions for seasonal crop detection. Sentinel 1 in particular is very promising for rice area estimation (Bouvet and Toan (2011); Nelson et al. (2014); RIICE - http://www.riice.org/; GEORice - http: //due.esrin.esa.int/page_project155.php). Future versions of PhenoRice could incorporate Sentinel 1 information for flood detection as well as Sentinel 2 information to allow more accurate identification of the rice area from which to sample with higher temporal frequency using moderate resolution.

The main innovative contribution of PhenoRice is to provide multiannual information on crop intensity and phenology to conduct wide area, long term analysis using moderate resolution satellite data archives. Preliminary studies conducted with this objective in the Senegal River Valley area showed very promising results, and identified a strong increase in rice cultivation in the dry season thanks to the improvement in irrigation practices (Busetto et al., 2016). However, the algorithm can also be applied in near real time monitoring applications to detect crop establishment and flowering following the logic of Combal and

This work is licensed under a Creative Commons "Attribution-NonCommercialNoDerivatives 4.0 International" license. 
Pre-print, submitted for publication to Remote Sensing of Environment. The final approved manuscript is available at 10.1016/j.rse.2017.03.029

Bartholomé (2008). Initial tests of this capability within the framework of the ERMES project have been promising and have been used to provide spatial explicit sowing date information as inputs to crop models for seasonal yield forecasting (Boschetti et al. (2015a); http://www. ermes-fp7space.eu).

\section{Conclusions}

Spatio-temporal information on staple crops is an essential component of regional crop monitoring applications. The most valuable contribution of moderate spatial but high temporal resolution optical remote sensing is in the temporal crop phenology/management domain as opposed to the area estimation domain, especially in fragmented landscapes where field sizes are substantially smaller than the pixel size. Despite this there are many more examples of area estimation than temporal information estimation in the literature.

Staple crops like rice are grown on a large extent in many countries in a range of environments which makes automated, rule-based methods for mapping and monitoring a very attractive solution. However rule-based methods for rice should be demonstrated as reliable and robust when considering the wide range of rice based cropping systems caused by the combination of the following factors:

- The diversity in genetics, environment and management (typically called GxExM interactions);

- The diversity of consumer and producer preferences for rice varieties;

- Complex and hard to measure socio-economic constraints;

- Localised, seasonal abiotic and biotic stresses.

We developed an algorithm, PhenoRice, to map three important temporal characteristics of rice cropping systems - rice cropping intensity, crop establishment date and flowering date - based on the relationship between spectral indices and rice crop management and development stages. The comparison of results from PhenoRice against high resolution, spatially explicit validation data in three diverse but representative rice cropping systems in Europe and Asia showed that the algorithm provided reliable and robust estimates of the spatio-temporal patterns of cropping intensity and crop establishment date. The identified diversity of combined vegetative and reproductive phases length per site also matched well with local information on crop establishment period and maturity of dominant varieties grown in the different cropping systems. Variations in the capability of the algorithm between and within sites was described and related to different crop establishment methods, water management, rice landscape fragmentation and quality of the MODIS imagery.

This work is licensed under a Creative Commons "Attribution-NonCommercialNoDerivatives 4.0 International" license. 
Pre-print, submitted for publication to Remote Sensing of Environment. The final approved manuscript is available at 10.1016/j.rse.2017.03.029

In conclusion, the results suggest that PhenoRice is a robust approach for deriving essential temporal descriptions of rice systems in both temperate and tropical regions. It can provide information at a level of spatial and temporal detail that is suitable for regional crop monitoring on a seasonal basis as well as providing information for crop yield models, crop health models and for rice system characterisation. PhenoRice is a contribution to operational remote sensing based methods for crop monitoring on a regional scale.

\section{Acknowledgments}

We thank the RIICE project (Remote Sensing-based Information for Insurance in Emerging economies) for providing high resolution SAR imagery in Tamil Nadu.

\section{Funding}

We thank the RIICE project (Remote Sensing-based Information for Insurance in Emerging economies) for providing high resolution SAR imagery in Tamil Nadu. We thank Liz Humphreys and Sudir Yadav for suggestions related to water management and crop establishment methods. We thank three anonymous reviewers for their comments and suggestions that improved this paper.

The research leading to these results was conducted within the ERMES FP7 project (http://www. ermes-fp7space.eu) which received funding from the European Union Seventh Framework Program (FP7/20072013) under grant agreement $n^{\circ} 606983$. A.N. was supported by the RIICE project, the PRISM project (Philippine Rice Information System) and the CGIAR Consortium Research Program for rice - GRISP (Global Rice Science Partnership). A.L. was supported by the PRISM project and GRISP.

\section{References}

Asilo, S., de Bie, K., Skidmore, A., Nelson, A., Barbieri, M., Maunahan, A., 2014. Complementarity of two rice mapping approaches: Characterizing strata mapped by hypertemporal modis and rice paddy identification using multitemporal SAR. Remote Sensing 6, 12789-12814. doi:10.3390/rs61212789.

Balasubramanian, V., Sie, M., Hijmans, R., Otsuka, K., 2007. Increasing Rice Production in Sub-Saharan Africa: Challenges and Opportunities. Advances in Agronomy 94, 55-133. doi:10.1016/S0065-2113(06) $94002-4$

Barbosa, P.M., Casterad, M.A., Herrero, J., 1996. Performance of several Landsat 5 Thematic Mapper (TM) image classification methods for crop extent estimates in an irrigation district. International Journal of Remote Sensing 17, 3665-3674. doi:10.1080/01431169608949176.

This work is licensed under a Creative Commons "Attribution-NonCommercialNoDerivatives 4.0 International" license. 
Pre-print, submitted for publication to Remote Sensing of Environment. The final approved manuscript is available at 10.1016/j.rse.2017.03.029

Biradar, C.M., Xiao, X., 2011. Quantifying the area and spatial distribution of double- and triple-cropping croplands in India with multi-temporal MODIS imagery in 2005. International Journal of Remote Sensing 32, 367-386. doi:10.1080/01431160903464179.

Bocchi, S., Callegarin, A., Baldi, G., 2003. Rice production system in Italy and its sustainability, in: INIA, U. (Ed.), Proceedings of the $3^{\text {rd }}$ Temperate Rice Conference, Punta del Este, Uruguay. pp. 12-22.

Boschetti, L., Flasse, S.P., Brivio, P.A., 2004. Analysis of the conflict between omission and commission in low spatial resolution dichotomic thematic products: The Pareto Boundary. Remote Sensing of Environment 91, 280-292. doi:10.1016/j.rse.2004.02.015.

Boschetti, M., Busetto, L., Nutini, F., Manfron, G., Crema, A., Confalonieri, R., Bregaglio, S., Pagani, V., Guarneri, T., Brivio, P.A., 2015a. Assimilating seasonality information derived from satellite data time series in crop modelling for rice yield estimation, in: 2015 IEEE International Geoscience and Remote Sensing Symposium (IGARSS), pp. 157-160. doi:10.1109/IGARSS. 2015.7325723.

Boschetti, M., Nelson, A., Nutini, F., Manfron, G., Busetto, L., Barbieri, M., Laborte, A., Raviz, J., Holecz, F., Mabalay, M., Bacong, A., Quilang, E., 2015b. Rapid Assessment of Crop Status: An Application of MODIS and SAR Data to Rice Areas in Leyte, Philippines Affected by Typhoon Haiyan. Remote Sensing 7, 6535-6557. doi:10.3390/rs70606535.

Boschetti, M., Nutini, F., Manfron, G., Brivio, P.A., Nelson, A., 2014. Comparative analysis of normalised difference spectral indices derived from MODIS for detecting surface water in flooded rice cropping systems. PLoS ONE 9, e88741. doi:10.1371/journal.pone.0088741.

Boschetti, M., Stroppiana, D., Brivio, P.A., Bocchi, S., 2009. Multi-year monitoring of rice crop phenology through time series analysis of MODIS images. International Journal of Remote Sensing 30, 4643-4662. doi:10.1080/01431160802632249.

Bouvet, A., Toan, T.L., 2011. Use of ENVISAT/ASAR wide-swath data for timely rice fields mapping in the Mekong River Delta. Remote Sensing of Environment 115, 1090-1101. URL: http://www . sciencedirect.com/science/article/pii/S0034425710003603, doi:10.1016/j.rse.2010.12.014.

Busetto, L., Boschetti, M., Zwart, S., Collivignarelli, F., 2016. Variations in rice cultivation practices in the Senegal river valley between 2003 and 2014: an analysis based on modis time series. ESA Living Planet Symposium 2016, Prague, 09/05/2016. URL: http://www.ermes-fp7space.eu/wp-content/uploads/ 2016/06/Poster_praga_senegal_v3.pdf. (Accessed on 2016-12-26).

Busetto, L., Ranghetti, L., 2016. MODIStsp: An R package for automatic preprocessing of MODIS Land Products time series. Computers \& Geosciences 97, 40-48. URL: http://www.sciencedirect.com/ 
Pre-print, submitted for publication to Remote Sensing of Environment. The final approved manuscript is available at 10.1016/j.rse.2017.03.029

science/article/pii/S0098300416303107, doi:10.1016/j.cageo.2016.08.020.

Calingacion, M., Laborte, A., Nelson, A., Resurreccion, A., Concepcion, J.C., Daygon, V.D., Mumm, R., Reinke, R., Dipti, S., Bassinello, P.Z., et al., 2014. Diversity of global rice markets and the science required for consumer-targeted rice breeding. PLoS ONE 9, e85106. doi:10.1371/journal.pone.0085106.

Camera di Commercio di Pavia, 2013. Analsi trimestrale sui prezzi e sul mercato del risone.

URL: http://www.pv.camcom.it/files/Rlilevazione_prezzi/Analisi_trimestrale_sui_prezzi_ e_sul_mercato_del_risone_nov13.pdf. (Accessed on 2016-12-26).

Chumkesornkulkit, K., Kasetkasem, T., Rakwatin P., Eiumnoh A., Kumazawa I., Buddhaboon C., 2013. Estimated rice cultivation date using an extended Kalman filter on MODIS NDVI time-series data, in: Conference on Electrical Engineering/Electronics, Computer, Telecommunications and Information Technology (ECTI-CON), 2013 10 ${ }^{\text {th }}$ International, pp. 1-6. doi:10.1109/ECTICon.2013.6559573.

Combal, B., Bartholomé, E., 2008. Retrieving phenological stages from low resolution Earth Observation data, in: Maselli, F., Menenti, M., Brivio, P. (Eds.), Optical observation of vegetation properties and characteristics. research signpost, trivandrum, kerala, india ed.. Research Signpost, pp. 115-131.

Confalonieri, R., Bocchi, S., 2005. Evaluation of CropSyst for simulating the yield of flooded rice in northern Italy. European Journal of Agronomy 23, 315-326. doi:10.1016/j .eja.2004.12.002.

CREA, 2015. Annuario dell'agricoltura italiana 2014. URL: http://www.crea.gov.it/wp-content/ uploads/2016/02/annuario2015_web.pdf. (Accessed on 2016-12-26).

Dawe, D., Pandey, S., Nelson, A., 2010. Emerging trends and spatial patterns of rice production, in: Pandey, S., Byerlee, D., Dawe, D., Dobermann, A., Mohanty, S., Rozelle, S., Hardy, B. (Eds.), Rice in the Global Economy: Strategic Research and Policy Issues for Food Security. International Rice Research Institute, Los Banos, Philippines, pp. 15-36.

Department of Evaluation and Applied Research (DEAR), 2014. Tamil nadu - an economic appraisal 201112 to 2013-14, chapter 4, page 54. URL: http://www.tn.gov.in/dear/Agriculture.pdf. (Accessed on 2016-12-26).

Didan, D., 2006. MOD13Q1 MODIS/Terra Vegetation Indices 16-Day L3 Global 250m SIN Grid V005. URL: http://www.icess.ucsb.edu/modis/LstUsrGuide/MODIS_LST_products_Users_guide_C5.pdf. (Accessed on 2016-12-26).

Duveiller, G., Baret, F., Defourny, P., 2011. Crop specific green area index retrieval from MODIS data at regional scale by controlling pixel-target adequacy. Remote Sensing of Environment 115, 2686-2701. doi:10.1016/j.rse.2011.05.026.

This work is licensed under a Creative Commons "Attribution-NonCommercialNoDerivatives 4.0 International" license. 
Pre-print, submitted for publication to Remote Sensing of Environment. The final approved manuscript is available at 10.1016/j.rse.2017.03.029

Ente Nazionale Risi, 2016. ENR statistics. URL: http://www.enterisi.it/servizi/Menu/dinamica. aspx? idSezione=17505\&idArea=17548\&idCat=17552\&ID=17552\&TipoElemento=categoria. (Accessed on 2016-12-26).

ERSAF, 2013. Carta Uso Agricolo Annuale (CUAA) - Land use map over Lombardy regional area. URL: http://www.ersaf.lombardia.it/servizi/Menu/dinamica.aspx?idSezione=16908\& idArea=16914\&idCat=17254\&ID=17254. (Accessed on 2016-12-26).

Fang, H., Wu, B., Liu, H., Huang, X., 1998. Using NOAA AVHRR and Landsat TM to estimate rice area year-by-year. International Journal of Remote Sensing 19, 521-525. doi:10.1080/014311698216134.

FAO, 2016. FAOSTAT. URL: http://faostat3.fao.org/. (Accessed on 2016-12-26).

Gond, V., Bartholomé, E., Ouattara, F., Nonguierma, A., Bado, L., 2004. Surveillance et cartographie des plans d'eau et des zones humides et inondables en régions arides avec l'instrument VEGETATION embarqué sur SPOT-4. International Journal of Remote Sensing 25, 987-1004. doi:10.1080/ 0143116031000139908.

Gray, J., Friedl, M., Frolking, S., Ramankutty, N., Nelson, A., Gumma, M.M.K., 2014. Mapping Asian Cropping Intensity With MODIS. IEEE Journal of Selected Topics in Applied Earth Observations and Remote Sensing 7, 3373-3379. doi:10.1109/JSTARS.2014.2344630.

GRiSP (Global Rice Science Partnership), 2013. Rice almanac, 4th edition. URL: http://books.irri. org/9789712203008_content.pdf. (Accessed on 2016-12-26).

GRiSP (Global Rice Science Partnership), 2016. Ricepedia. URL: http://ricepedia.org/ rice-around-the-world/europe. (Accessed on 2016-12-26).

Group on Earth Observation, 2013. Progress on GEOGLAM Implementation: First steps towards Implementation 2013-2014 Phase I and II, Document 10 (rev1). URL: http://www.earthobservations.org/ documents/geoglam/GEOGLAM_Implementation_Plan.pdf. (Accessed on 2016-12-26).

Gumma, M.K., Nelson, A., Thenkabail, P.S., Singh, A.N., 2011. Mapping rice areas of South Asia using MODIS multitemporal data. Journal of Applied Remote Sensing 5, 053547. doi:10.1117/1.3619838.

Haefele, S., Nelson, A., Hijmans, R., 2014. Soil quality and constraints in global rice production. Geoderma 235-236, 250-259. doi:10.1016/j.geoderma.2014.07.019.

Hijmans, R.J., Cameron, S.E., Parra, J.L., Jones, P.G., Jarvis, A., 2005. Very high resolution interpolated climate surfaces for global land areas. International Journal of Climatology 25, 1965-1978. doi:10.1002/ joc. 1276 .

Huete, A., Didan, K., Miura, T., Rodriguez, E., Gao, X., Ferreira, L., 2002. Overview of the radiometric and

This work is licensed under a Creative Commons "Attribution-NonCommercialNoDerivatives 4.0 International" license.

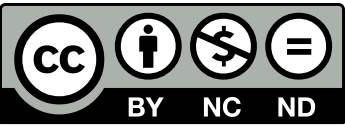


Pre-print, submitted for publication to Remote Sensing of Environment. The final approved manuscript is available at 10.1016/j.rse.2017.03.029

biophysical performance of the MODIS vegetation indices. Remote Sensing of Environment 83, $195-213$. doi:10.1016/S0034-4257(02) 00096-2.

International Rice Research Institute (IRRI), 2016. Rice Knowledge Bank. URL: http://www. knowledgebank.irri.org/index.php?option=com_zoo\&task=item\&item_id=1114\&Itemid=819. (Accessed on 2016-12-26).

JECAM, 2015. Joint experiment of crop assessment and monitoring. URL: http://www.jecam.org. (Accessed on 2016-12-26).

Laborte, Alice G.and Paguirigan, N.C., Moya, P.F., Nelson, A., Sparks, A.H., Gregorio, G.B., 2015. Farmer's preference for rice traits: Insights from farm surveys in Central Luzon, Philippines, 1966-2012. doi:10. 7910/DVN/OA6XHO. (Accessed on 2016-12-26).

Le Toan, T., Ribbes, F., Floury, N., Fujita, M., Kurosu, T., 1997. Rice crop mapping and monitoring using ERS-1 data based on experiment and modeling results. IEEE Transactions on Geoscience and Remote Sensing 35, 41-56. doi:10.1109/36.551933.

Leroux, L., Jolivot, A., Bégué, A., Seen, D.L., Zoungrana, B., 2014. How Reliable is the MODIS Land Cover Product for Crop Mapping Sub-Saharan Agricultural Landscapes? Remote Sensing 6, 8541. URL: http: //www.mdpi.com/2072-4292/6/9/8541, doi:10.3390/rs6098541.

Li, Y., Liao, Q., Li, X., Liao, S., Chi, G., Peng, S., 2003. Towards an operational system for regional-scale rice yield estimation using a time-series of Radarsat ScanSAR images. International Journal of Remote Sensing 24, 4207-4220. doi:10.1080/0143116031000095970.

Manfron, G., Crema, A., Boschetti, M., Confalonieri, R., 2012. Testing automatic procedures to map rice area and detect phenological crop information exploiting time series analysis of remote sensed MODIS data, in: Stein, K., Gonglewski, J. (Eds.), SPIE Remote Sensing, p. 85311E. doi:10.1117/12.974662.

Manjunath, K., More, R.S., Jain, N., Panigrahy, S., Parihar, J., 2015. Mapping of rice-cropping pattern and cultural type using remote-sensing and ancillary data: a case study for South and Southeast Asian countries. International Journal of Remote Sensing 36, 6008-6030. doi:10.1080/01431161.2015.1110259.

Mosleh, M., Hassan, Q., 2014. Development of a remote sensing-based "boro" rice mapping system. Remote Sensing 6, 1938-1953. doi:10.3390/rs6031938.

Moya, P., Kajisa, K., Barker, R., Mohanty, S., Gascon, F., San Valentin, M., 2015. Changes in Rice Farming in the Philippines: Insights from five decades of a household-level survey. URL: http://books.irri. org/9789712203152_content.pdf.

Nelson, A., Setiyono, T., Rala, A.B., Quicho, E.D., Raviz, J.V., Abonete, P.J., Maunahan, A.A., Garcia,

This work is licensed under a Creative Commons "Attribution-NonCommercialNoDerivatives 4.0 International" license. 
Pre-print, submitted for publication to Remote Sensing of Environment. The final approved manuscript is available at 10.1016/j.rse.2017.03.029

C.A., Bhatti, H.Z.M., Villano, L.S., Thongbai, P., Holecz, F., Barbieri, M., Collivignarelli, F., Gatti, L., Quilang, E.J.P., Mabalay, M.R.O., Mabalot, P.E., Barroga, M.I., Bacong, A.P., Detoito, N.T., Berja, G.B., Varquez, F., Wahyunto, Kuntjoro, D., Murdiyati, S.R., Pazhanivelan, S., Kannan, P., Nirmala Mary, P.C., Subramanian, E., Rakwatin, P., Intrman, A., Setapayak, T., Lertna, S., Minh, V.Q., Tuan, V.Q., Duong, T.H., Quyen, N.H., Van Kham, D., Hin, S., Veasna, T., Yadav, M., Chin, C., Ninh, N.H., 2014. Towards an operational SAR-based rice monitoring system in Asia: Examples from 13 demonstration sites across Asia in the RIICE project. Remote Sensing 6, 10773-10812. doi:10.3390/rs61110773.

Nguyen, T.T.H., De Bie, C.A.J.M., Ali, A., Smaling, E.M.A., Chu, T.H., 2012. Mapping the irrigated rice cropping patterns of the Mekong delta, Vietnam, through hyper-temporal SPOT NDVI image analysis. International Journal of Remote Sensing 33, 415-434. doi:10.1080/01431161.2010.532826.

Pazhanivelan, S., Kannan, P., Christy Nirmala Mary, P., Subramanian, E., Jeyaraman, S., Nelson, A., Setiyono, T., Holecz, F., Barbieri, M., Yadav, M., 2015. Rice crop monitoring and yield estimation through COSMO Skymed and TerraSAR-X: A SAR-based experience in India. International Archives of the Photogrammetry, Remote Sensing and Spatial Information Sciences - ISPRS Archives 40, 85-92. doi:10.5194/isprsarchives-XL-7-W3-85-2015.

Peng, D., Huete, A.R., Huang, J., Wang, F., Sun, H., 2011. Detection and estimation of mixed paddy rice cropping patterns with MODIS data. International Journal of Applied Earth Observation and Geoinformation 13, 13-23. doi:10.1016/j.jag.2010.06.001.

Philippines Statistics Authority, 2016. CountrySTAT Philippines: Subnational Palay and Corn Area harvested by ecosystem/croptype by quarter, by semester, by region and province. URL: http: //countrystat.psa.gov.ph/?cont=10\&pageid=1\&ma=080LUAHC. (Accessed on 2016-12-26).

Ranghetti, L., Busetto, L., Crema, A., Fasola, M., Cardarelli, E., Boschetti, M., 2016. Testing estimation of water surface in Italian rice district from MODIS satellite data. International Journal of Applied Earth Observation and Geoinformation 52, 284-295. doi:10.1016/j.jag.2016.06.018.

Regione Piemonte, 2011. Piedmont Region Land Use Map 2011. URL: http://www.sistemapiemonte. it/sitad/metadata_1.do?idEntita=10002716\&interfaccia=sispie\&authType=guest. (Accessed on 2016-12-26).

Roy, D., Boschetti, L., 2009. Southern Africa validation of the MODIS, L3JRC, and GlobCarbon burnedarea products. IEEE Transactions on Geoscience and Remote Sensing 47, 1032-1044. doi:10.1109/TGRS. 2008. 2009000 .

Sakamoto, T., Van Nguyen, N., Ohno, H., Ishitsuka, N., Yokozawa, M., 2006. Spatio-temporal distribution

This work is licensed under a Creative Commons "Attribution-NonCommercialNoDerivatives 4.0 International" license.

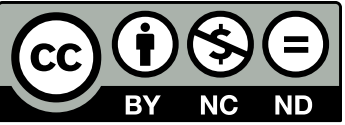


Pre-print, submitted for publication to Remote Sensing of Environment. The final approved manuscript is available at 10.1016/j.rse.2017.03.029

of rice phenology and cropping systems in the Mekong Delta with special reference to the seasonal water flow of the Mekong and Bassac rivers. Remote Sensing of Environment 100, 1-16. doi:10.1016/j.rse. 2005.09 .007$.

Sakamoto, T., Yokozawa, M., Toritani, H., Shibayama, M., Ishitsuka, N., Ohno, H., 2005. A crop phenology detection method using time-series MODIS data. Remote Sensing of Environment 96, 366-374. doi:10. $1016 / j . r s e .2005 .03 .008$

Suwannachatkul, S., Kasetkasem, T., Chumkesornkulkit, K., Rakwatin, P., Chanwimaluang, T., Kumazawa, I., 2014. Rice cultivation and harvest date identification based on a hidden Markov model, in: 2014 $11^{\text {th }}$ International Conference on Electrical Engineering/Electronics, Computer, Telecommunications and Information Technology (ECTI-CON), IEEE. pp. 1-6. doi:10.1109/ECTICon.2014.6839856.

Templeton, D., Bayot, R., 2011. Aerobic Rice - responding to water scarcity: An impact assessment of the 'Developing a System of Temperate and Tropical Aerobic Rice (STAR) in Asia' project. URL: https://assets.publishing.service.gov.uk/media/57a08ad040f0b649740007be/IA05_Star_ templeton_april11_final_web.pdf. (Accessed on 2016-12-26).

Tornos, L., Huesca, M., Dominguez, J.A., Moyano, M.C., Cicuendez, V., Recuero, L., Palacios-Orueta, A., 2015. Assessment of MODIS spectral indices for determining rice paddy agricultural practices and hydroperiod. ISPRS Journal of Photogrammetry and Remote Sensing 101, 110-124. doi:10.1016/j . isprsjprs.2014.12.006.

Turner, M.D., Congalton, R.G., 1998. Classification of multi-temporal SPOT-XS satellite data for mapping rice fields on a West African floodplain. International Journal of Remote Sensing 19, 21-41. doi:10.1080/ 014311698216404.

Waldner, F., Fritz, S., Di Gregorio, A., Defourny, P., 2015. Mapping priorities to focus cropland mapping activities: Fitness assessment of existing global, regional and national cropland maps. Remote Sensing 7, 7959. URL: http://www.mdpi.com/2072-4292/7/6/7959, doi:10.3390/rs70607959.

Wan, Z., 2006. Collection-5 MODIS Land Surface Temperature Products Users'Guide. URL: http://www . icess.ucsb.edu/modis/LstUsrGuide/MODIS_LST_products_Users_guide_C5.pdf. (Accessed on 2016$12-26)$.

Wassmann, R., Jagadish, S., Heuer, S., Ismail, A., Redona, E., Serraj, R., Singh, R., Howell, G., Pathak, H., Sumfleth, K., 2009. Chapter 2 Climate Change Affecting Rice Production: The Physiological and Agronomic Basis for Possible Adaptation Strategies. Advances in Agronomy 101, 59-122. URL: http: //wWw.sciencedirect.com/science/article/pii/S006521130800802X.

This work is licensed under a Creative Commons "Attribution-NonCommercialNoDerivatives 4.0 International" license. 
Pre-print, submitted for publication to Remote Sensing of Environment. The final approved manuscript is available at 10.1016/j.rse.2017.03.029

Whitcraft, A.K., Becker-Reshef, I., Justice, C.O., 2015. A framework for defining spatially explicit earth observation requirements for a global agricultural monitoring initiative (GEOGLAM). Remote Sensing 7, 1461-1481. doi:10.3390/rs70201461.

Xiao, X., Boles, S., Frolking, S., Li, C., Babu, J.Y., Salas, W., III, B.M., 2006. Mapping paddy rice agriculture in South and Southeast Asia using multi-temporal MODIS images. Remote Sensing of Environment 100, 95-113. doi:10.1016/j.rse.2005.10.004.

Xiao, X., Boles, S., Frolking, S., Salas, W., Moore, B., Li, C., He, L., Zhao, R., 2002. Observation of flooding and rice transplanting of paddy rice fields at the site to landscape scales in China using VEGETATION sensor data. International Journal of Remote Sensing 23, 3009-3022. doi:10.1080/01431160110107734.

Xiao, X., Boles, S., Liu, J., Zhuang, D., Frolking, S., Li, C., Salas, W., Moore, B., 2005. Mapping paddy rice agriculture in southern China using multi-temporal MODIS images. Remote Sensing of Environment 95, 480-492. doi:10.1016/j.rse.2004.12.009.

This work is licensed under a Creative Commons "Attribution-NonCommercialNoDerivatives 4.0 International" license. 